\title{
Coevolutionary Dynamics of Organic-Inorganic Interactions, Hydrocarbon Generation, and Shale Gas Reservoir Preservation: A Case Study from the Upper Ordovician Wufeng and Lower Silurian Longmaxi Formations, Fuling Shale Gas Field, Eastern Sichuan Basin
}

\author{
Zhijun Jin $\mathbb{D}^{1,2}$ Haikuan Nie, ${ }^{1,2}$ Quanyou Liu, ${ }^{1,2}$ Jianhua Zhao, ${ }^{3}$ Ruyue Wang ${ }^{D},{ }^{1,2}$ \\ Chuanxiang Sun, ${ }^{1,2}$ and Guanping Wang ${ }^{4}$ \\ ${ }^{1}$ State Key Laboratory of Shale Oil and Gas Enrichment Mechanisms and Effective Development, Beijing 100083, China \\ ${ }^{2}$ Sinopec Petroleum Exploration and Production Research Institute, Beijing 100083, China \\ ${ }^{3}$ College of Geosciences, China University of Petroleum, Qingdao 266580, China \\ ${ }^{4}$ School of Energy Resources, China University of Geosciences, Beijing 100083, China \\ Correspondence should be addressed to Zhijun Jin; jinzj1957@pku.edu.cn
}

Received 3 October 2020; Revised 15 November 2020; Accepted 2 December 2020; Published 22 December 2020

Academic Editor: Loupasakis Constantinos

Copyright (c) 2020 Zhijun Jin et al. This is an open access article distributed under the Creative Commons Attribution License, which permits unrestricted use, distribution, and reproduction in any medium, provided the original work is properly cited.

\begin{abstract}
Shale gas deposits are self-sourced, self-accumulating, and self-preserving in the Upper Ordovician Wufeng Formation and Lower Silurian Longmaxi Formation of the Fuling Shale Gas Field in the eastern Sichuan Basin. They were both seemingly mixed by secondary oil cracking and kerogen cracking gases during the high maturation window. The reservoir space primarily consists of mineral pores and organic matter $(\mathrm{OM})$ pores, and the shale gas was mainly trapped by a high-pressure system. In this study, the Fuling $\mathrm{O}_{3} w-\mathrm{S}_{1} l$ Shale Gas Field in the eastern Sichuan Basin was used as a case study to discuss the coevolutionary process and organic-inorganic interactions of hydrocarbon generation, accumulation, and preservation. The results indicate that the processes and mechanisms of organic-inorganic interactions and coevolution of hydrocarbon generation and reservoir preservation are quite different among the shale graptolite zones (GZ) with respect to hydrocarbon generation, types and characteristics of shale gas reservoirs, seal characteristics, and their spatiotemporal relations. In the WF2-LM4 GZ, the favorable $\mathrm{OM}$, biogenic authigenic quartz and organic-inorganic interactions are highly coupled, leading to the high level of coevolution demonstrated within the field, as well as to the favorable conditions for shale gas accumulation. Conversely, the overlying LM5LM8 GZ seemingly exhibits early densification and late charge and has a reverse mode of reservoir development (i.e., low degree of coevolution). These two coevolutionary processes were conducive to the development of a high degree of spatiotemporal matching between the reservoir (i.e., WF2-LM4 GZ) and the seal (i.e., LM5-LM8 GZ). This is due to underlying differences in their coevolutionary histories. The synthetic work presented here on the coevolutionary processes and mechanisms of formation for organic-inorganic interactions and hydrocarbon generation and reservoir preservation reveals insights into the driving mechanisms of shale gas enrichment, providing a basis for effectively predicting favorable enrichment intervals for shale gas worldwide.
\end{abstract}

\section{Introduction}

During the past 10 years, most of the research on shale gas reservoirs has focused on source rock [1-3], reservoir types, porosity, and pore structure [4-11]. Most importantly, the pores within organic matter $(\mathrm{OM})$ are widely recognized as a significant component of pore systems in gas-bearing shales $[9,10,12-18]$. A greater potential for gas storage and flow exists in higher total organic carbon (TOC) content intervals, depending on the abundance and connectivity of the OM 
pores $[8,16,19]$. Therefore, shale gas reservoirs are mainly evaluated using TOC content, thermal maturity, rock mineralogy, rock brittleness, and porosity and permeability $[1,2$, 20]. However, the combination of pore types, especially with respect to their components, characteristics, and organicinorganic interactions during the evolution of the shale reservoir, are less well known. This has restricted our understanding of the diagenetic and pore evolution histories, and the accuracy with which we may evaluate reservoir potential. The pore formation and the evolutionary histories and proportion of OM porosity are the key information needed to ascertain the effectiveness of exploration as well as the associated production capacity of shale gas reservoirs.

Porosity-related variances are directly related to differences in the amount and character of the OM and mineralogical composition [21-23]. The pore formation history is composed of the inorganic-organic interactions between OM (i.e., hydrocarbon generating organisms and/or bitumen) and inorganic matter (i.e., minerals such as quartz, feldspar, pyrite, and calcite). Organic-inorganic interactions in sandstones have been documented [24-26], and many important insights have been gained on the growth of minerals, the preservation of the pores that are affected by hydrocarbon charge $[27,28]$, and the effects of minerals on the hydrocarbon generation of OM [29]. Meanwhile, the driving processes behind diagenetic pathways in shales [10, 30, 31], the nature of pores in shales, and the controls on porosity evolution remain poorly known [17]. Additionally, this does not take into consideration the effects of hydrocarbon generation and expulsion processes on mineral diagenesis, mineral pore evolution, and the relationship between organic (hydrocarbon generation) and inorganic (reservoir evolution) coevolutionary processes.

The petroleum retained along with kerogen and shale mineralogy may be a critical factor in shale gas generation [32], but their coevolutionary dynamics are little known. More attention is needed to develop our understanding of the coevolutionary processes that drive organic-inorganic interactions, hydrocarbon generation, and reservoir development of shale gas reservoir [20]. OM and inorganic minerals are not considered as unidirectional, simple, and determinate in their relations, but rather as a kind of interactional and coevolutionary relationship. The interaction between OM and inorganic minerals leads to their coevolution. The interaction is the foundation and motivation, and the coevolution is the process and consequence; both of them are achieved through physical and chemical processes. The key issue centers on how OM and inorganic minerals may interact to achieve coevolution, thus forming the reservoir types and characteristics that we observe as well, as the shale gas reservoir. Furthermore, the specific mechanisms and corresponding developmental states of pore systems (organic and inorganic) are deserving of more attention. Due to the particular system of self-contained, self-sourced, and selfaccumulating reservoir, the qualitative and semiquantitative evaluation of the organic-inorganic coevolutionary process may be conducted through the comprehensive analysis of hydrocarbon generation history, reservoir developmental processes, and preservation.
This study systematically analyzed the coevolutionary process and mechanisms of hydrocarbon generation and reservoir preservation based on organic geochemistry, mineralogy, pore characterization, seal characteristics, and the corresponding evolutionary history, combined with shale gas exploration and development in the largest Lower Paleozoic shale gas field in the world at Fuling, in the eastern Sichuan Basin. The results reveal the mechanism of shale gas enrichment in the Fuling Shale Gas Field and provide insights into the organic-inorganic interactive process and pore development, especially of the OM pore network within the studied shales. This may provide the basis for effective predicting favorable enrichment intervals of the Upper Ordovician Wufeng Formation and Lower Silurian Longmaxi Formation shale gas worldwide.

\section{Geological Setting}

As a superimposed basin developed on the upper Yangtze Craton, the Sichuan Basin is one of the most tectonically stable sedimentary basins in China [33]. Surrounded by the Hubei-Hunan-Guizhou Fold Belt on the east, the Longmenshan Fold Belt on the west, the Micang Uplift and Dabashan Fold Belt sitting on the north, and the Emei-Liangshan Fold Belt on the south, the basin can be divided into three tectonic regions and six sublevel tectonic units by the Huayingshan and Longquanshan anticlines [34] (Figure 1). Several tectonic movements occurred in the Sichuan Basin which in chronological order are the Caledonian (Cambrian-Silurian), Hercynian (Devonian-Permian), Indosinian (Triassic), Yanshanian (Jurassic-Late Cretaceous), and Himalayan (Paleogene-Quaternary) orogenies [34-36]. Sedimentary sequences of the basin are relatively complete, which include the Middle-Upper Proterozoic, Paleozoic, Mesozoic, and Cenozoic strata. Currently, China's largest gas yield comes from the Sichuan Basin which has the most prolific natural gas resources [33].

The black shale in the $\mathrm{O}_{3} w-\mathrm{S}_{1} l$ Fuling Shale Gas Field (i.e., Wufeng and Longmaxi Formations) was deposited in a low-energy anoxic sedimentary environment, from the Late Ordovician to Early Silurian [38]. The maximum thicknesses of the formations of the $\mathrm{O}_{3} w-\mathrm{S}_{1} l$ Fuling Shale Gas Field are between 30 and $100 \mathrm{~m}$. In the Sichuan Basin and its surrounding areas where main China's shale gas yield comes from, the Wufeng and Longmaxi Formations have been the main targets for shale gas exploration, development, and production in recent years, leading to the establishment of three national shale-gas demonstration areas including the Fuling, Weiyuan-Changning, and Zhaotong.

To get a fine classification of shales with similar content, biostratigraphy can be an effective method when it is difficult to use lithology, mineral composition, geochemical parameters, and petrophysical properties. In a biostratigraphic study, graptolite is one of the leading globally recognized index fossil groups, which is a basis for fine shale division of the shales in the Wufeng Formation and the Longmaxi Formation [39]. Since specific graptolite types were only developed and preserved in the specific sedimentary environment during a specific period, the specific shales can be recognized and clarified 


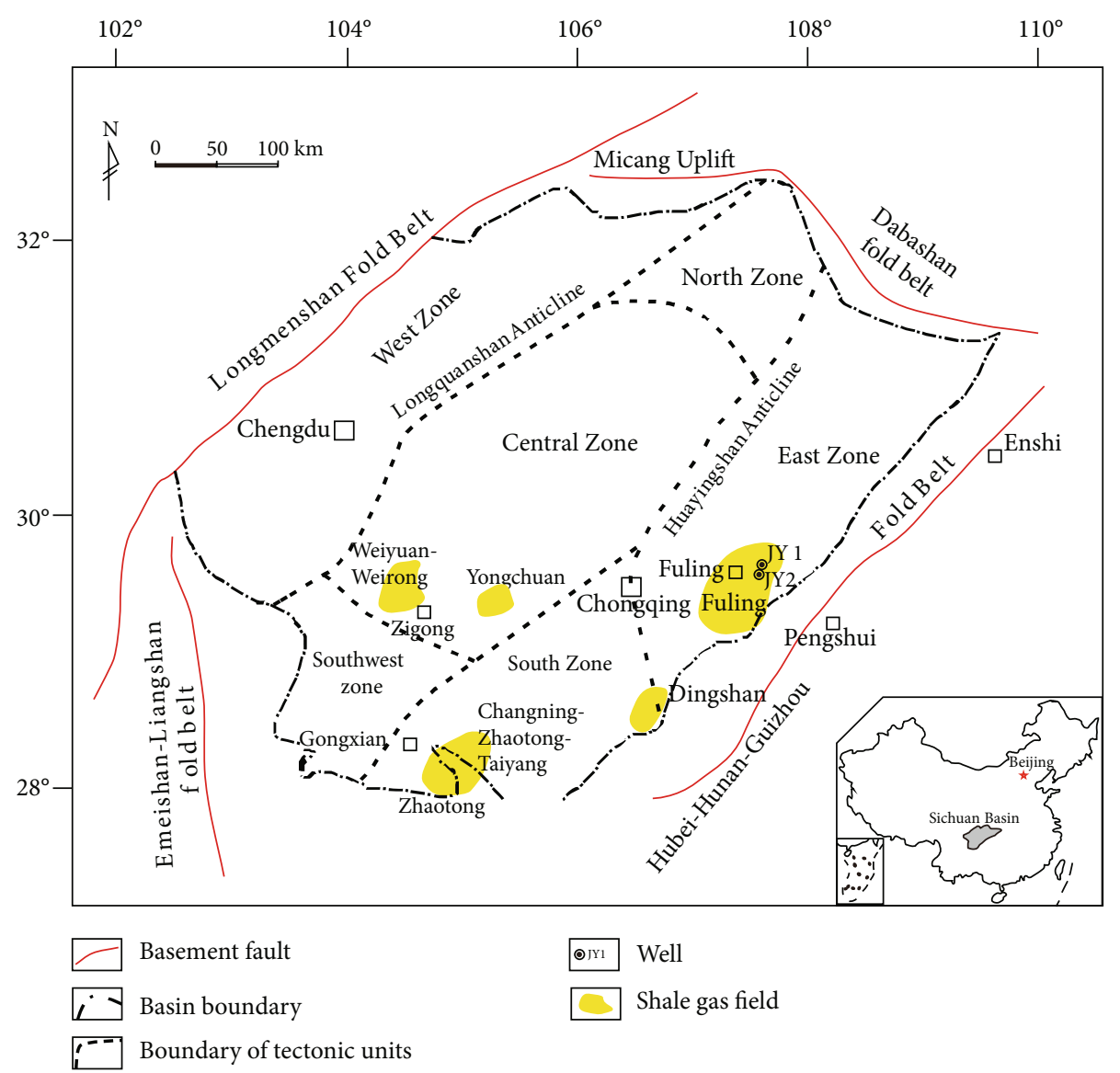

Figure 1: Location map of the study area in the Sichuan Basin, China; the structural subdivisions include the eastern, southern, western, northern, southeastern, and central zones (after [37]).

[39-41]. Both the assemblage of hydrocarbon-forming organisms in different shale intervals and the shale quality were of great difference [42]. During the depositional period of the Wufeng Formation and the Longmaxi Formation, shale thickness and organic carbon content are changing; thus, it was more accurate to describe with a timeline the gradual development of shale characteristics based on the graptolite zone $[39,43]$. According to the GZ divisions in the Wufeng and Longmaxi Formations $[39,40]$, the shales have been divided into WF1-WF4 in the Wufeng Formation and LM1-LM9 in the Longmaxi Formation.

\section{Samples and Methods}

More than 100 black shale samples from the Upper Ordovician Wufeng Formation-Lower Silurian Longmaxi Formation are used and sourced mainly from the shale-gas wells in the Sichuan basin and its periphery (Figure 1). The fieldemission scanning electron microscopy (FE-SEM) observation was conducted at the State Key Laboratory of Biochemical Engineering at the Institute of Process Engineering, Chinese Academy of Sciences. The other data in this study were obtained from the experiments conducted at the State Key Laboratory of Shale Oil and Gas Enrichment Mechanisms and Effective Development at the China Petroleum \& Chemical Corporation.

\section{Source Rock}

4.1. Kerogen Type and Hydrocarbon-Generating Organisms. The thickness of the gas-bearing black shales in Upper Ordovician Wufeng Formation-Lower Silurian Longmaxi Formation in the XYZ region ranges from $83.5 \mathrm{~m}$ to $102 \mathrm{~m}$. The basal $38-44 \mathrm{~m}$ of black shale contains $>2 \%$ TOC over a large area [44]. Measured shale porosity from the JY 1 Well averaged $4.5 \%$, and the gas content in the basal $38 \mathrm{~m}$ of black shales was around $2.99 \mathrm{~m}^{3} / \mathrm{t}$ [44]. The main kerogen type in the WF2-LM8 GZ is considered to be dominated by Type II kerogen with some Type I [45], which favors the development of the OM pores [9]. And the development of OM pores between WF2-LM4 GZ and LM5-LM8 GZ is controlled by hydrocarbon-forming organisms [20,37].

Organic-rich sediments that lack terrigenous organic matter indicate a phytoplankton source [46]. Pelagic deposition of phytoplankton is interpreted as a primary mechanism of organic matter deposition, which is converted to hydrocarbons and matrix bitumen [36]. Based on the morphology, inherited texture, and energy spectrum, the OM can be linked to several hydrocarbon-generating organisms. This includes primary $\mathrm{OM}$, such as various algae (multicellular algae, unicellular algae, acritarchs, etc.), graptolites, sponge spicules, and various types of secondary OM, such as bitumen, which occurs as discrete amorphous OM, and small 
organic domains or organoclay aggregates [42]. Different hydrocarbon-generating organisms exist in different sedimentary environments, leading to the diversity of the type and content of OM, hydrocarbon-generating capacity, and OM pore development ability.

The multicellular algae include red, brown, and other planktonic algae. Pores within algal OM, particularly in smaller porous OM domains, are similar in shape, size, and distribution and may also be influenced by the original structure of the algae [16]. The diameter of single multicellular algae (probably red algae) ranges from several $\mu \mathrm{m}$ to tens of $\mu \mathrm{m}$. Intense compaction may deform the shape of multicellular algae. The multicellular algae bear a mix of OM and silica since some of them have siliceous shells [42]. Other identified algae which present no siliceous shells fill in the mineral pores with their size varying with the size of mineral pores (Figure 2). Without the protection of the siliceous shell, the shape of the algae can be easily altered. Under strong compaction, the algae shape deformation caused by internalstructure rearrangement of $\mathrm{OM}$ exhibits directionalalignment and/or flow-like structures in the narrow mineral pores. No directional alignment of the OM has been observed in circular or approximately equant mineral pores or in the center of narrow mineral pores, due to the insignificant difference in the degree of OM compaction.

The unicellular algae include blue, green, and other benthic algae. Unicellular algae mainly include rhabditiform blue algae (also known as cyanobacteria) and spherical algae and usually gather to form colonies (Figure 3). The diameter or length of its colony is several $\mu \mathrm{m}$ to tens of $\mu \mathrm{m}$. The length of single rhabditiform blue algae is a few hundred $\mathrm{nm}$ to more than $1 \mu \mathrm{m}$, and the width is a few hundred $\mathrm{nm}$, while the spherical algae are circular or oval and have uneven surfaces and rough edges; some developed pores ranging tens of $\mathrm{nm}$ in size.

The red, brown, and other planktonic algae which can take advantage of green, yellow, orange, and other short wavelengths dominate the deep water zone, while the green algae, cyanobacteria, and other benthic algae are common in shallow waters [47, 48]. The hydrocarbon-generating organisms of the WF2-LM4 GZ are primarily the red, brown, and other planktonic algae living in the aerobic surface layer and preserved in a strongly reducing environment in the bottom water [37]. A small amount of terrigenous OM is found in the hydrocarbon-generating organisms of the WF2-LM4 GZ [49]. In comparison, the hydrocarbon-generating organisms of the LM5-LM8 GZ were predominated by green algae, cyanobacteria, siliceous sponges, and other benthic algae, as well as a small amount of red, brown, and other planktonic algae [37]. TOC content is largely determined by different sources of hydrocarbon-forming organisms. The highest TOC content of $4.97 \%$ on average is found in siliceous mudstone of WF2-LM4 GZ; higher TOC content varying from $2.01 \%$ to $3.77 \%$ with an average of $2.84 \%$ appears in the silica-bearing mudstone of WF2-LM4 GZ. TOC contents of LM5-LM8 GZ are from $1.32 \%$ to $2.68 \%$ with an average of $1.70 \%$ in the silty mudstone and $0.60 \%-2.53 \%$ with an average of $1.59 \%$ in the clay-rich mudstone (Figure 4 ). The WF2LM4 GZs are where siliceous mudstone and silica-bearing mudstone are prevalent and have the high production of shale gas wells.

4.2. Hydrocarbon Generation History. According to the burial history of Well JY 1, the black shale in the Wufeng and Longmaxi Formations underwent three stages of hydrocarbon generation (Figure 5): (1) The initial stage was the rapid subsidence and burial in the Early Devonian. Buried at a depth less than $2000 \mathrm{~m}$, thermal maturity (vitrinite reflectance, $R_{\mathrm{o}}$ ) of the black shale was about $0.5 \%$ generating a small amount of heavy oil. The black shale was uplifted in the middle Devonian to the Late Permian when hydrocarbon generation was suspended. (2) The second stage was in the Early-Middle Triassic when the subsidence occurred. When the burial depth of the black shale went up to $3000 \mathrm{~m}$, its thermal maturity climbed to about $1.0 \%$, reaching the peak oil generation window. In the Middle-Late Triassic, again the black shale was uplifted and hydrocarbon generation was suspended, but because of a rapid, limited-amplitude uplift, oil expulsion efficiency was low, leaving a large amount of crude oil in the shale. (3) Subsidence from the early Jurassic to middle Cretaceous was the third stage. Black shale was buried at a depth greater than $7000 \mathrm{~m}$ with thermal maturity greater than $2.5 \%$, turning into the overmature dry gas generation window. Residual kerogen and oil cracked generating plentiful shale gas as well as a large number of porous pyrobitumen which provided a huge number of $\mathrm{OM}$ pores for gas storage. After the Late Cretaceous, the black shale was uplifted again during which the generation of shale gas was terminated. The thermal maturity data range from $2.2 \%$ to $3.13 \%$ was present, with the mean value of $2.65 \%$ [20], suggesting the OM is already in the overmature stage.

According to Montgomery et al. [50], the Barnett Shale in the Fort Worth Basin of Texas, USA, was buried in a shallow depth and then uplifted for a long period during the early evolution stage, then was deeply buried in a short time and uplifted quickly in the middle evolution stage, and was quickly buried and uplifted in the late evolution stage. Similar characteristics have been found when comparing the burial and thermal evolution history of the shale from the Wufeng Formation and Longmaxi Formation in the Sichuan Basin (Figure 5). During the early stages of their burial history from Early Silurian to Late Permian, both experienced long-term shallow burial and uplift, which was favorable for the kerogen preservation allowing a limited amount of hydrocarbon generation and expulsion. During the second period from EarlyMiddle Triassic to Late Triassic, short-term burial and uplift led to a large amount of crude oil generation and retention. Finally, the late period from the early Jurassic to recent witnessed rapid subsidence and uplift which was unfavorable for gas discharging, but favorable for shale gas generation, accumulation, and preservation.

\section{Reservoir Rock}

5.1. Mineral Composition. There are some differences in the sedimentary environments among GZs, and this is reflected in the mineral composition. During the Late Ordovician to the Early Silurian, the black shale of the WF2-LM4 GZ was 


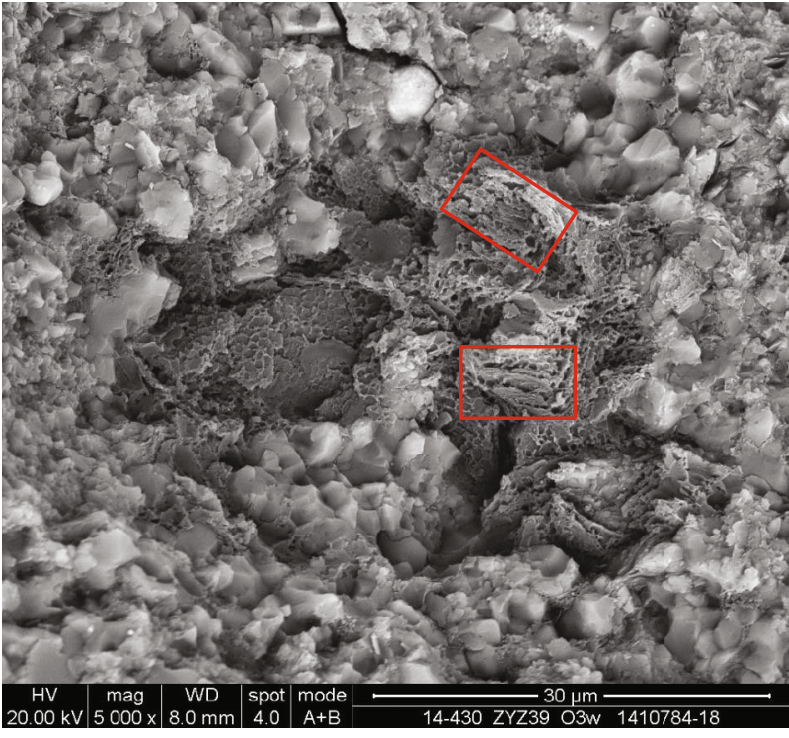

(a)

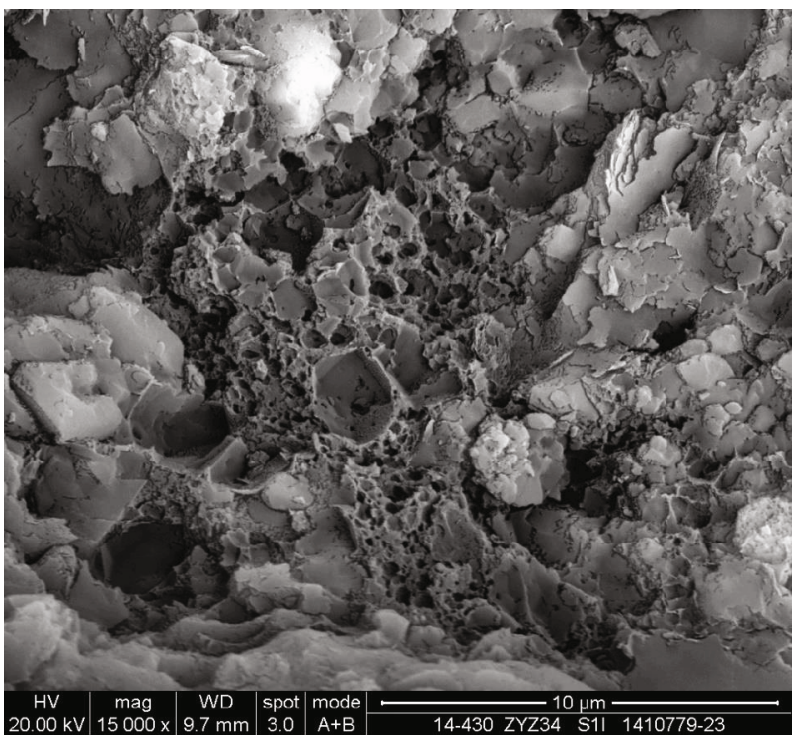

(b)

FIGURE 2: Multicellular algae in black shale. (a) The overview of the profile; many multicellular algae can be observed. The aligned OM pores in the red panel probably indicate that the algae have inherent variation in their internal structure (well JY 2, 2570.89 m (WF2 GZ), the TOC content is $3.66 \%$ and the $R_{\mathrm{o}} \%$ is $2.65 \%$ ). (b) unaligned OM pores (well JY 2, $2556.91 \mathrm{~m}$ (LM4 GZ), the TOC content is $3.9 \%$ and the $R_{\mathrm{o}} \%$ is $2.46 \%)$.

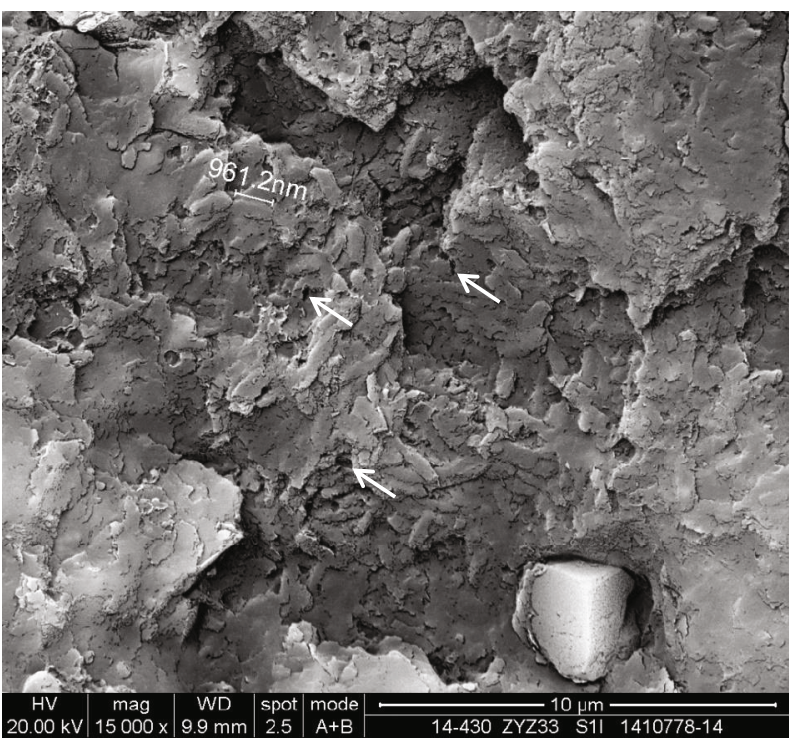

(a)

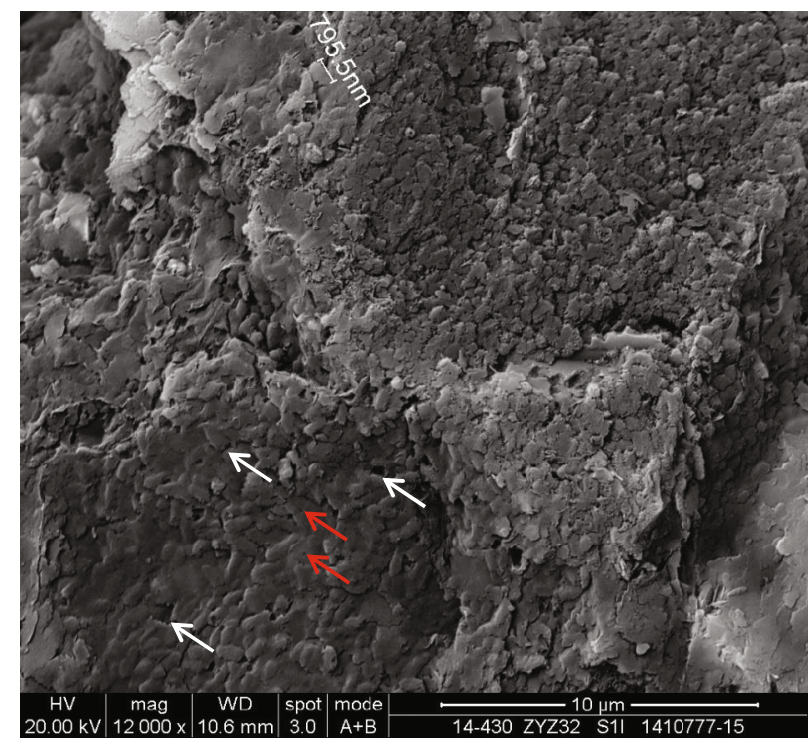

(b)

FIgURE 3: Unicellular algae in black shale. (a) Rhabditiform blue algae colonies and OM pores (white arrows) observed in the Longmaxi Formation black shale (well JY 2, $2543.84 \mathrm{~m}$ (LM5 GZ), the TOC content is $3.8 \%$ and the $R_{\mathrm{o}} \%$ is $2.55 \%$ ). (b) Spherical nanoscale algae colonies; small pores (red arrow) and large pores (white arrow). The OM pore is developed by the arrangement gaps of the algae (well JY $2,2523.11 \mathrm{~m}$ (LM6 GZ), the TOC content is $2.11 \%$ and the $R_{\mathrm{o}} \%$ is $2.63 \%$ ).

deposited in a low-energy, anoxic environment [36, 51]. The mineral composition of 87 shale samples from the JY 1 Well are as follows: (1) In the WF2-LM4 GZ: the content of quartz, clay, feldspar, calcite, dolomite, pyrite, and hematite accounts for $31.0 \%-70.6 \%, \quad 16.6 \%-49.1 \%, 3.2 \%-11.3 \%, 0 \%-7.5 \%, 0$ $31.5 \%, 0-4.8 \%$, and $0-7.5 \%$ with the averages of $46.6 \%, 31.6 \%$, $7.9 \%, 4.1 \%, 6.9 \%, 0.79 \%$, and $2.2 \%$, respectively. (2) In the LM5-LM8 GZ, the content of quartz, clay, feldspar, calcite, dolomite, pyrite, and hematite accounts for $18.4 \%-51.4 \%$, $33.3 \%-62.8 \%, 4.6 \%-15.0 \%, 0-11.8 \%, 0-30.9 \%, 0-1.9 \%$, and $0-$ $4.9 \%$, respectively. Averages were $33.1 \%, 45.1 \%, 10.0 \%, 3.6 \%$, $5.9 \%, 0.03 \%$, and $2.4 \%$, respectively. Compared to the LM5LM8 GZ, the WF2-LM4 zone has a higher quartz content and a lower clay content (Figure 4), which is similar to the distributions observed for the Barnett and Eagle Ford shales [3, 52], which favor the accumulation and production of shale gas. 


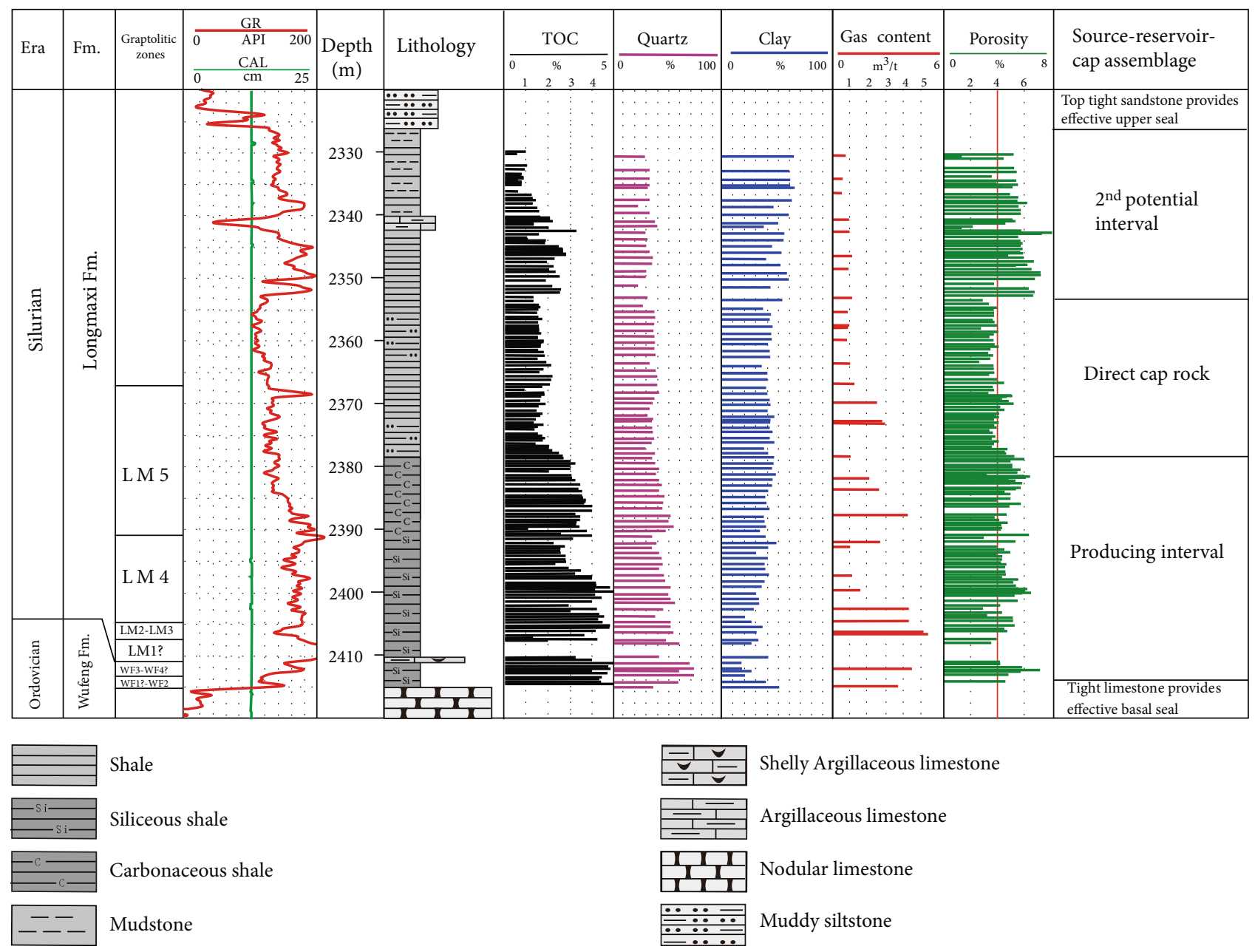

FIGURE 4: Comprehensive evaluation histogram showing favorable interval for shale gas exploration in JY 1 Well (modified from [20]) with the upper boundary of the producing interval in the middle of the LM5 GZ. The mineral composition is obtained by X-ray diffraction, and the gas content is based on on-site desorption of shale.

Mineralogy may also be an important factor that controls both pore types and porosity preservation due to the differences in the ability to resist mechanical compaction. Siliceous mineral content is an important geological parameter in evaluating the quality and potential of shale reservoirs [52]. Thus, the content and origin of quartz must be resolved. Two different types of quartz, namely, detrital quartz and porefilling authigenic quartz, have been identified through petrographic observations, cathodoluminescence (CL), and SEM analysis [53]. The quartz content of shales in the JY 1 Well has a positive correlation with the corresponding TOC content. However, this statistic ignores the differences between siliceous minerals and TOC in different GZs. Further analysis reveals that the quartz content of the WF2-LM4 GZ is mainly greater than $40 \%$ which is dominated by biogenic silica [44]. It displays a strong positive correlation with TOC, guaranteeing a high matching of siliceous mineral and TOC. An increase in bioclastic components correlates with higher TOC content due to the higher volume of an organic-rich matrix. In contrast, the quartz content of the LM6-LM8 GZ varying from $20 \%$ to $40 \%$ is dominated by terrigenous silica, displaying no correlation with TOC content. As a continuous depositional transition between LM4 and LM6, the LM5 GZ has variable quartz content as a result of both terrigenous silica as well as biogenic silica. Siliceous shale is the main shale type of the WF2-LM4 gas-producing section, and the siliceous content is generally greater than $40 \%$. Silica is often cryptocrystalline and amorphous, exhibiting spherical structures (Figures 6(a) and 6(b)), and there are usually sponge spicules and skeletal material, including radiolarian fragments (Figures 6(c) and 6(d)).

The detrital versus an authigenic form of quartz can be discriminated firstly by crystal shape and spatial distribution and then by color and intensity in CL. CL can also be used to determine quartz provenance [52, 54-56]. Low-luminescent or nonluminescent quartz observed in scanning monocathodoluminescence electron microscope is commonly attributed to a low-temperature, authigenic/diagenetic origin $[54,55]$. In this study, a resolution SEM with monocathodoluminescence and energy-dispersive $\mathrm{X}$ ray spectroscopy (EDS) detectors were used to identify the provenance of quartz within the Wufeng and Longmaxi Formation shales. Two different types of quartz were identified [57]: (1) Biogenic microcrystalline quartz 


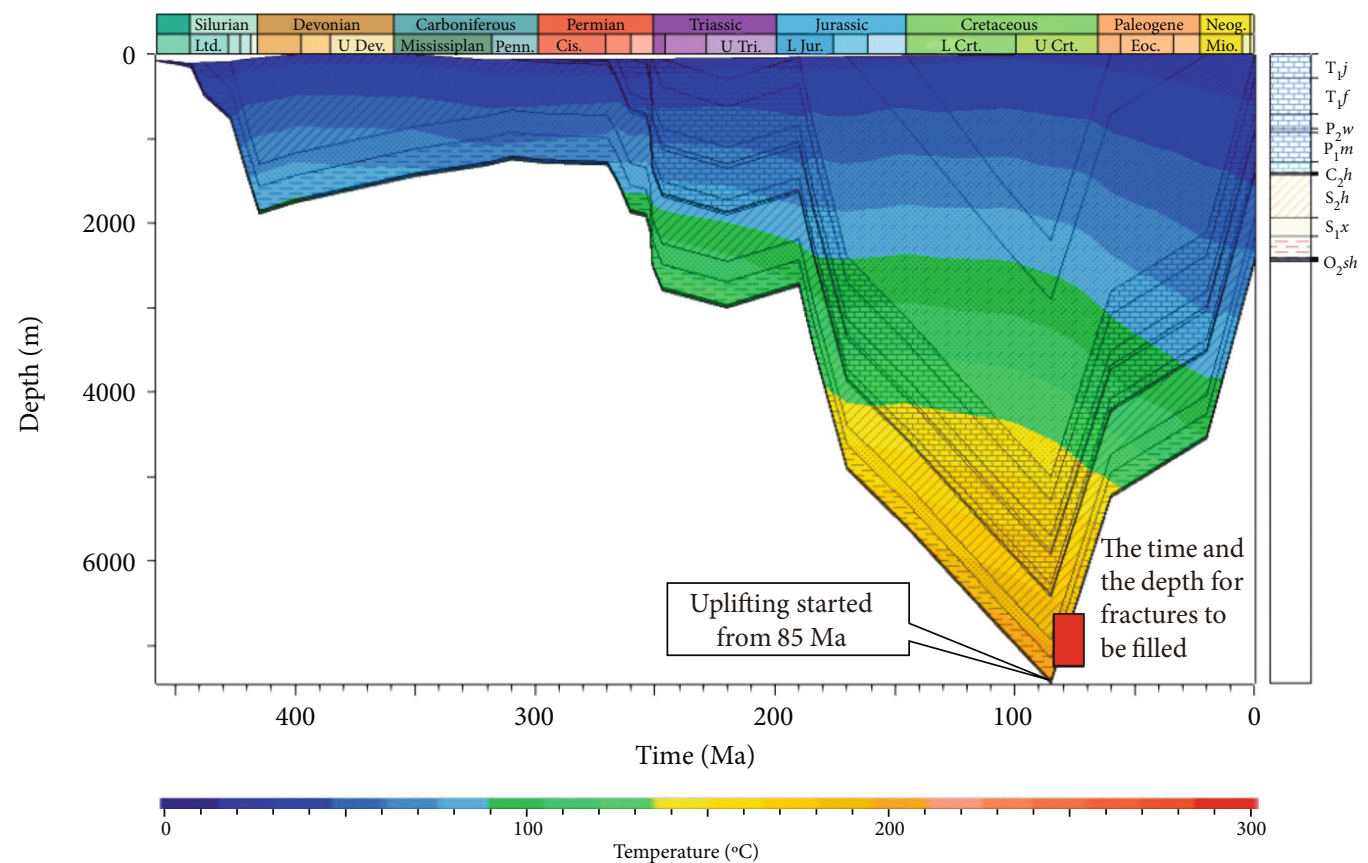

(a)

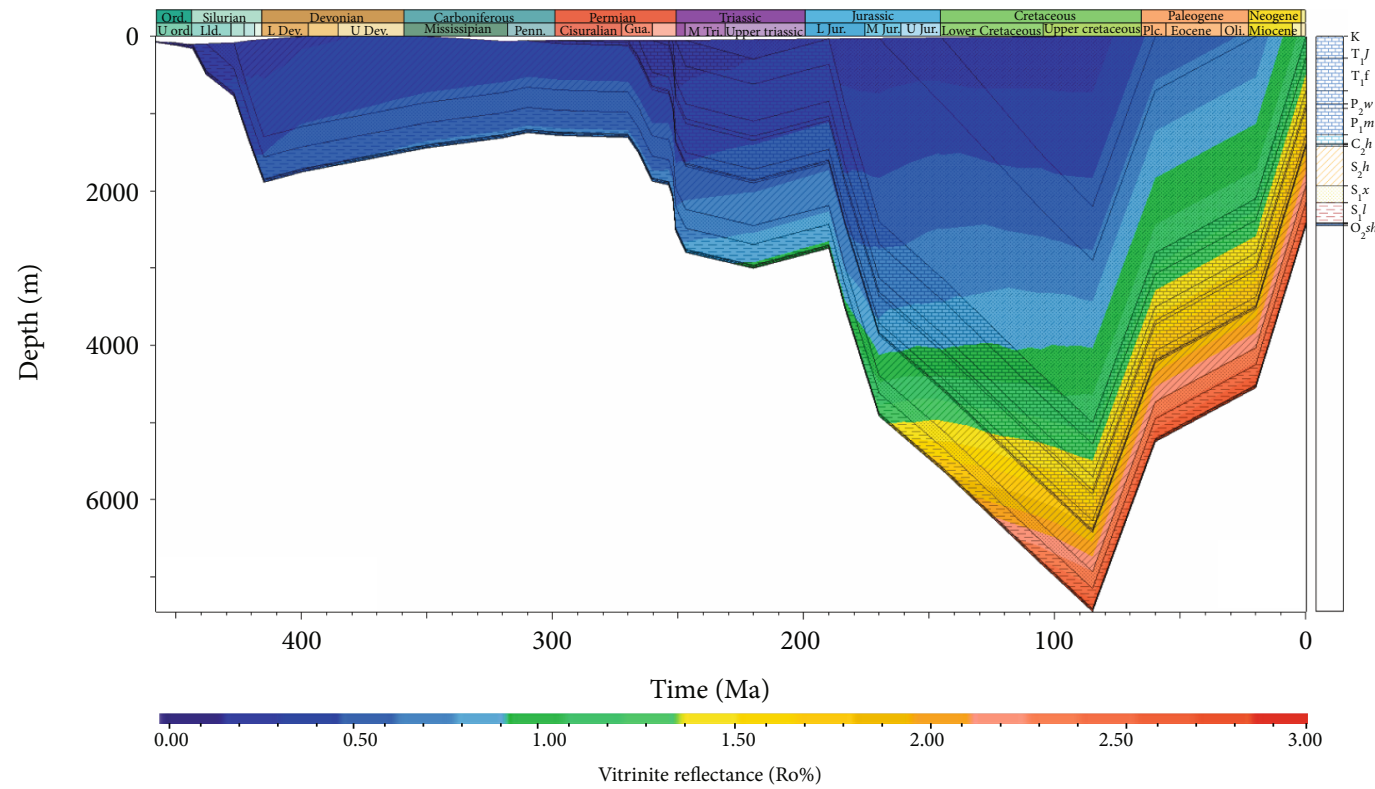

(b)

FiguRE 5: Burial-history reconstruction for JY 1 Well in the Sichuan Basin: (a) Superimposed history of temperature changes; (b) Superimposed history of thermal maturity $R_{\mathrm{o}}$. The well's location is in Figure 1. The model was built through the PetroMod software. Compaction and uplift were based on thermal maturity calibrated by the thermal maturity data of Wufeng Formation-Longmaxi Formation shales and measured borehole temperatures. JY 1 Well. K: Cretaceous; $\mathrm{T}_{1} j$ : Jialingjiang Formation in the Triassic; $\mathrm{T}_{1} d$ : Daye Formation in the Triassic; $\mathrm{T}_{1} f$ : Feixianguan Formation in the Triassic; $\mathrm{P}_{2} w$ : Wujiaping Formation in the Permian; $\mathrm{P}_{1} m$ : Maokou Formation in the Permian; $\mathrm{P}_{1} q$ : Qixia Formation in the Permian; $\mathrm{P}_{1} l$ : Liangshan Formation in the Permian; $\mathrm{C}_{2} h$ : Huanglong Formation in the Carboniferous; $\mathrm{S}_{2} h$ : Hanjiadian Formation in the Silurian; $\mathrm{S}_{1} x$ : Xiaoheba Formation in the Silurian; $\mathrm{S}_{1} l$ : Longmaxi Formation in the Silurian; $\mathrm{O}_{2}$ : Middle Ordovician (Baota Formation-Shizipu Formation); $\mathrm{O}_{2}$ sh: Shizipu Formation in the Ordovician.

(1-3 $\mu \mathrm{m})$ and irregular microcrystalline aggregates among the detrital grains that were weakly luminescent or nonluminescent (Figure 7). Biogenic microcrystalline quartz produces a broad luminescence peak between $620 \mathrm{~nm}$ and $660 \mathrm{~nm}$ (Figure 7(c)), which is similar to the luminescence generated by low-temperature authigenic quartz due to oxygen vacancies [55]. (2) Silt-size quartz grains (5$20 \mu \mathrm{m})$ are characterized by a uniform luminescence intensity (Figures 7 and 8). The subrounded and subangular silt-sized quartz grains produce two luminescence peaks with wavelengths of between 390 and $420 \mathrm{~nm}$ and 620$640 \mathrm{~nm}$ (Figure $8(\mathrm{c})$ ), suggesting a detrital origin [56]. 


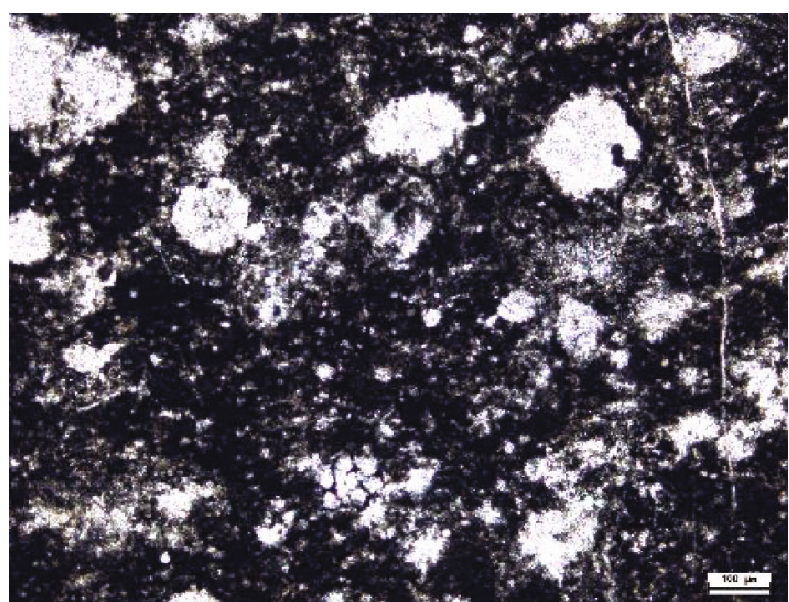

(a)

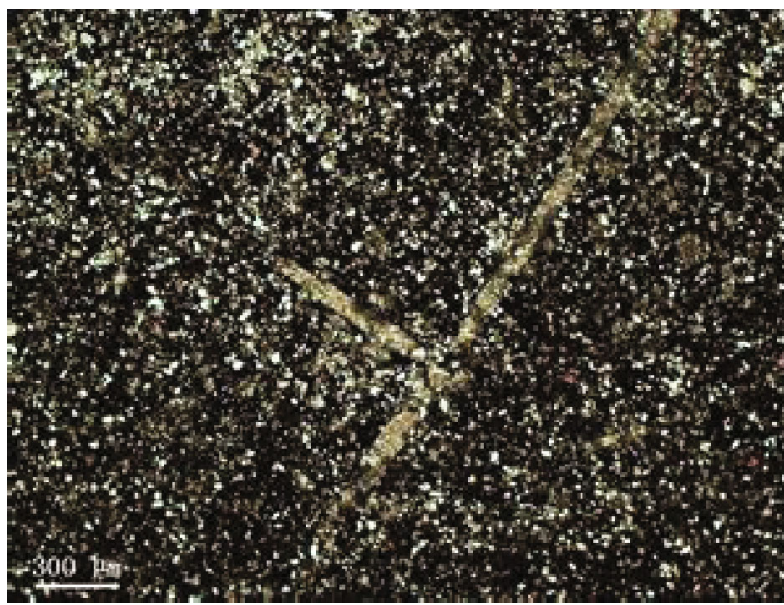

(c)

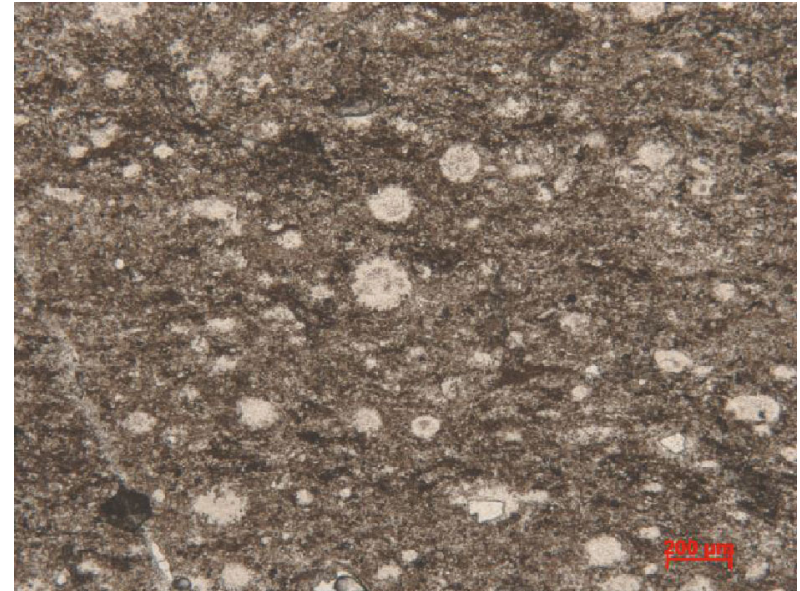

(b)

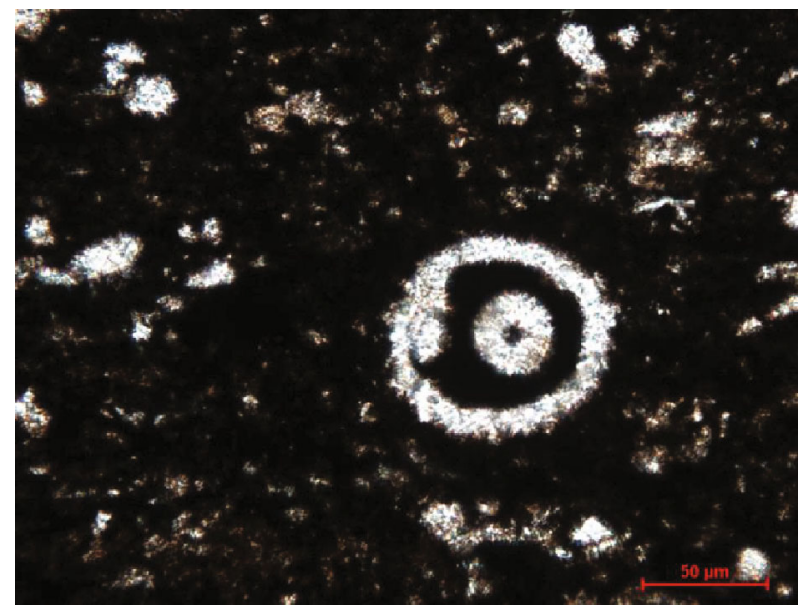

(d)

Figure 6: Intrabasinal biosiliceous debris in Wufeng and Longmaxi Formations, Fuling Shale Gas Field, Sichuan Basin. (a) Suspected pellet structure contains fossils and has an ellipsoid shape due to compaction, well JY 2, $\mathrm{O}_{3} w, 2570.9 \mathrm{~m}$; (b) quartz with ellipsoid shapes, presumably siliceous minerals filling the cysts of algae at the early stage of diagenesis, well JY 2, $\mathrm{O}_{3} w, 570.9 \mathrm{~m}$; (c) radiolarians, Well JY 1, $\mathrm{S}_{1} l, 2389.3 \mathrm{~m}$; (d) sponge spicule, well JY 2, $\mathrm{S}_{1} l, 2545.2 \mathrm{~m}$.

The bulk of opaline silica produced by dissolved biogenic silica of radiolarians and sponge spicules in ocean surface waters does not become incorporated into deep-sea sediments because it dissolves while settling down [54]. Sediment accumulation rate is a significant factor in mudrock cementation [58], especially for the formation of biogenic quartz. In the situation in which there was a slow rate of sediment accumulation in the WF2-LM4 GZ, the amount of dissolved biogenic silica from radiolarian tests and sponge spicules is substantial. In contrast, rapidly deposited shales of the LM5-LM8 GZ tend to have only trace amounts of biogenic silica. In the processes of burial and exposure to high temperatures and pressures, the biogenic opal- $\mathrm{A}$ is first transformed into opal-CT and eventually into biogenic quartz $[52,54]$, which is mainly composed of aphanitic, microcrystalline, and macrocrystalline quartz. This may be the reason why there is more biogenic silica in the WF2-LM4 GZ than in the LM5-LM8 GZ. Up to $60 \%$ of total quartz has a biogenic origin in siliceous shales of the WF2-LM4 GZ [57], resembling the Eagle Ford Formation in Texas, in which the authi- genic quartz comprises $85 \%$ percent and is equal to about $12.6 \%$ by volume [52]. There is more biogenic silica in the WF2-LM4 GZ than the silt-size detrital quartz in siliceous shales of the LM5-LM8 GZ. Biogenic quartz cement as matrix-dispersed microcrystalline quartz plays an important role in the diagenesis of the Wufeng and Longmaxi Formations.

Microcrystalline quartz in siliceous shales is mainly formed during diagenesis and is similar to the microcrystalline quartz in the Barnett Shale [3] and Eagle Ford Shale [52]. Thin section analysis and other methods reveal that there are different hydrocarbon-generating fossil organisms in the WF2-LM4 GZ. In addition to the graptolites, algae, and acritarchs, there are many siliceous microfossils, such as radiolarians, sponge spicules, and other skeletal fragments (Figure 6), which indicate the organic origin of silica in the organic-rich shale of the WF2-LM4 GZ. The content of detrital quartz and feldspar in siliceous shales is relatively low, which is the main difference between the organic-rich and the silty shale (the main shale type of LM5-LM8 GZ). 


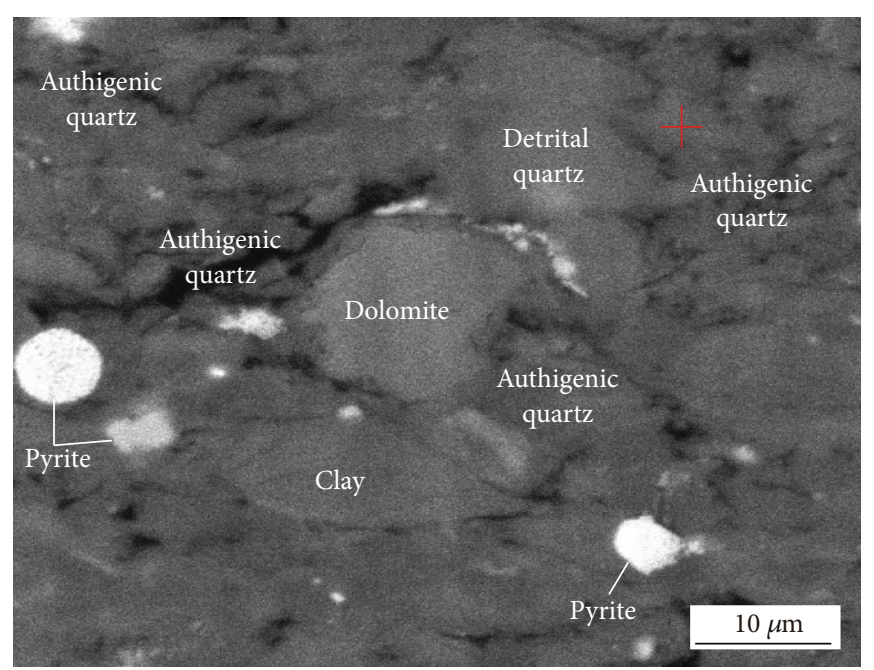

(a)

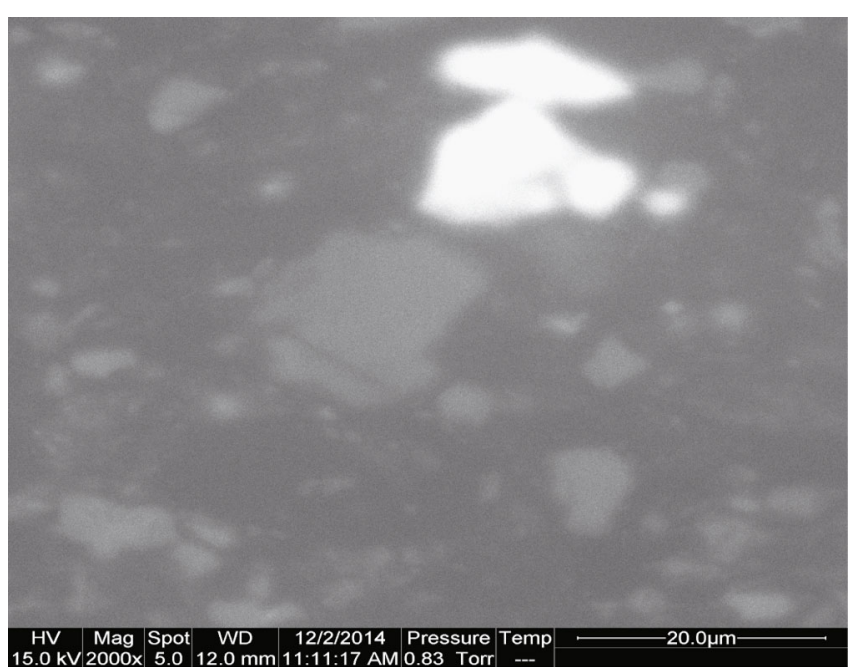

(b)

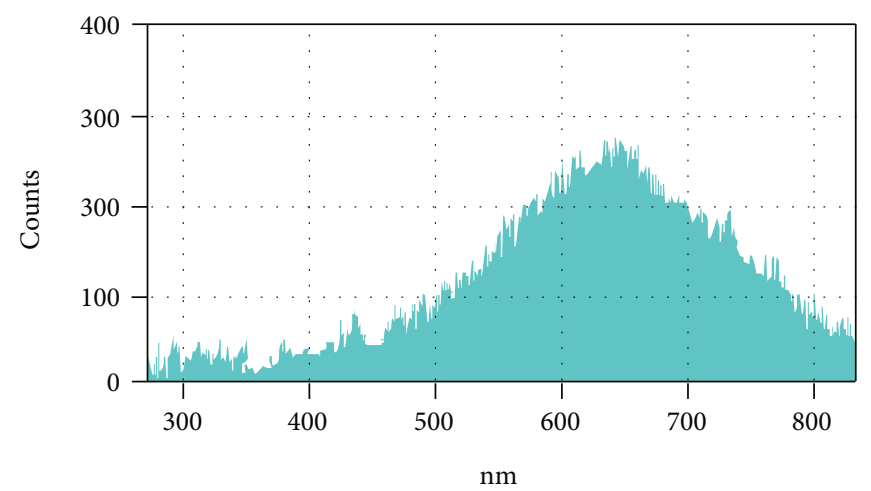

(c)

FIGURE 7: BSE images, cathodoluminescence (CL) image, and CL-response images of siliceous shale samples from the Wufeng and Longmaxi Formations. (a) BSE image of detrital quartz silt with pore-filling authigenic quartz, Longmaxi Formation, 2565.85 m, well JY 2. (b) SEM-CL image reveals that quartz silt grains have strong luminescence. In contrast, microcrystalline quartz is essentially nonluminescent, suggesting a diagenetic origin. (c) Monochromatic CL-responses of microcrystalline quartz (red cross in (a)).

Radiolarians and sponge spicules are the dominant forms of silica in the intrabasinal detrital assemblage. Dissolved silica released by dissolution of the radiolarians and sponge spicules is the dominant source of silica for the precipitation and reprecipitation of authigenic quartz in a variety of forms, including matrix-dispersed microcrystalline quartz cement, and fillings within primary intragranular pores [52]. The matrix-dispersed biogenic quartz is the dominant quartz in WF2-LM4 GZ(Figures 7 and 8). The matrix-dispersed authigenic microcrystalline quartz in the Wufeng and Longmaxi Formations occurs as the grain-binding cement that plays a role in the generation of brittle mechanical rock properties, similar to the Barnett Shale [30]. Additionally, the specific form of matrix-dispersed authigenic quartz has significant implications for the rock mechanical properties and residual oil. Moreover, as a result of precipitating authigenic quartz from the dissolution of biogenic opal [54], preserved quartz content (i.e., excess silica) may also reflect the surface water productivity during deposition [59], which indicates a higher surface productivity with a higher supply of OM during shale deposition.
5.2. Pore Types. The pore types in the Wufeng and Longmaxi Formations include OM pores, inorganic mineral pores (particle-related, pyrite-related, and clay-related pores), and microfractures $[10,11,33]$; the most important of these are the OM pores. Greater gas storage and flow capacity exist in shale intervals with higher TOC and depend upon the abundance and connectivity of OM pores $[7,10,14,60]$. Observations demonstrate a complex evolution of the $\mathrm{OM}$ pore system in shales [60]. The difference in OM types (hydrocarbon-generating organisms and amorphous OM (bitumen)) has an impact on the type, size, and distribution of the OM pore system [42]. The OM type, controlled by sequence-stratigraphic position [13], is a key factor in determining the pore type, size, and distribution. The OM pores include pores hosted in algae, biodetritus, and bitumen. The algae are a structured OM type, which generally has consistent or predictable porosity styles in the shale section due to the different algal types. Proceeding from the bottom of the Wufeng Formation to the middle and upper parts of the first member of the Longmaxi Formation, the OM pore types and pore size changed regularly. 


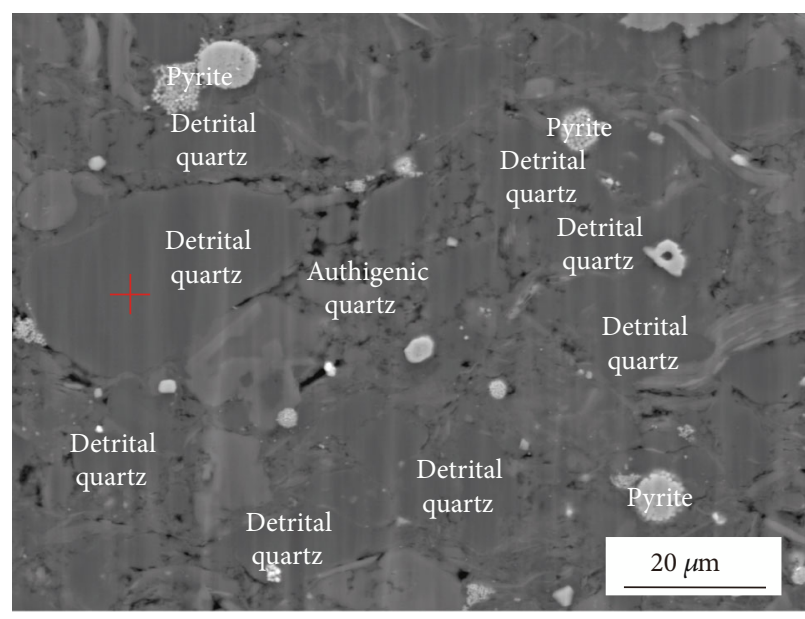

(a)

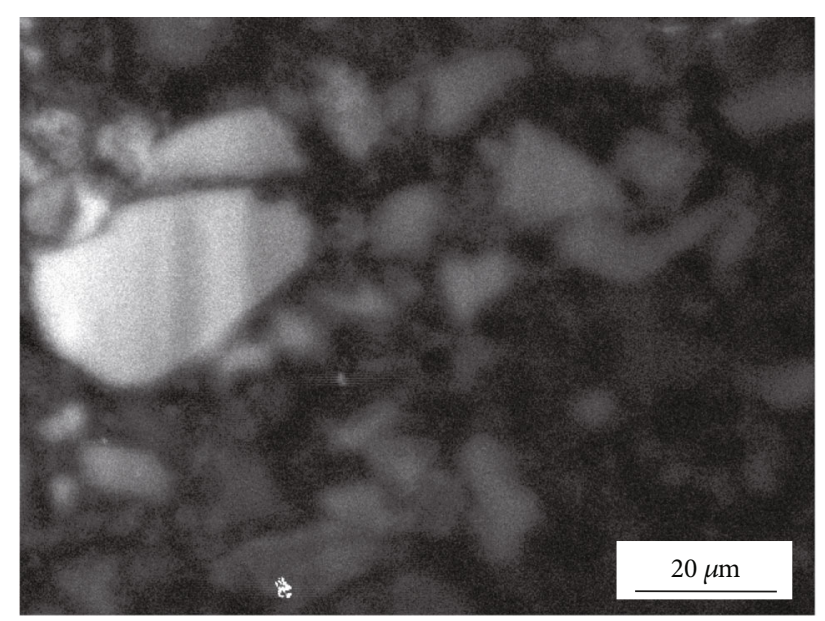

(b)

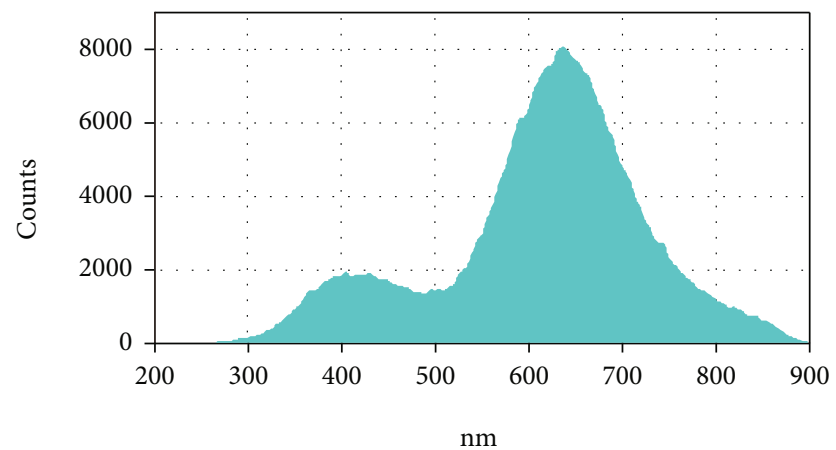

(c)

FIGURE 8: BSE images, cathodoluminescence (CL) image, and CL-response images of siliceous shale samples from the Wufeng and Longmaxi Formations. (a) BSE image of detrital quartz silt with pore-filling authigenic quartz, Wufeng Formation, 2532.11 m, well JY 2. (b) SEM-CL image displaying the strong luminescence of quartz silt grain. (c) Monochromatic CL-responses of quartz silt (blue cross in (a)).

(1) The shale of the WF2-LM4 GZ was found to be the interval with the most abundant OM present, in which the most abundant type of OM is multicellular algae, as well as small amounts of unicellular algae and bitumen [42]. Under compaction, the OM formed thin layers and/or three-dimensional interconnected OM pore networks (Figure 2). The OM pores were left behind by various hydrocarbon-generating organisms (mainly multicellular algae) and oil during gas generation and expulsion. The high total amounts of multicellular algae ensure a large number of OM pores, favoring the formation of three-dimensional interconnected pore networks, which is conducive to the enrichment and production of shale gas. Additionally, the three-dimensional reconstruction of kerogen and porosity distributions reveal that OM pores have the potential to form connected pore networks, where $26 \%-67 \%$ of the pore volume may be connected [16]. Moreover, the mineral pores are predominately slitlike in the cross-section, whereas OM pores are typically round [11]. OM pore networks are a combination of pores developed in depositional OM and migrated OM [14]. The depositional OM (mainly multicellular algae) pores are the main reservoir type in the shale of the WF2-LM4 GZ [37].
(2) The OM types of the LM5-LM8 GZ are mainly composed of unicellular algae and amorphous OM (bitumen), and the TOC is lower than the shale of the WF2-LM4 GZ [19]. The OM pores are mainly developed in unicellular algae and/or little in solid bitumen which often occur as poorly developed isolated pores and in unicellular algae which tended to be randomly developed by the arrangement gaps (Figure 3 ). Therefore, this kind of OM pore development is limited. The shape is irregular, and the size is tens to more than one hundred $\mathrm{nm}$. The OM pore system changes are less pronounced and cannot form three-dimensional interconnected $\mathrm{OM}$ pore networks due to the low TOC content, which is not conducive to the enrichment and production of shale gas.

\section{Direct Seal}

A series of tight strata directly overlying the shale gas reservoir is served as the cap rock, such as shale, silty shale, argillaceous siltstone, and limestone. A prerequisite for shale gas source and seal coupling systems is the heterogeneity of shale strata, while key factors determining the capability of the direct seal are lithology and petrophysical properties, as well as the differences of petrophysical parameters between the 

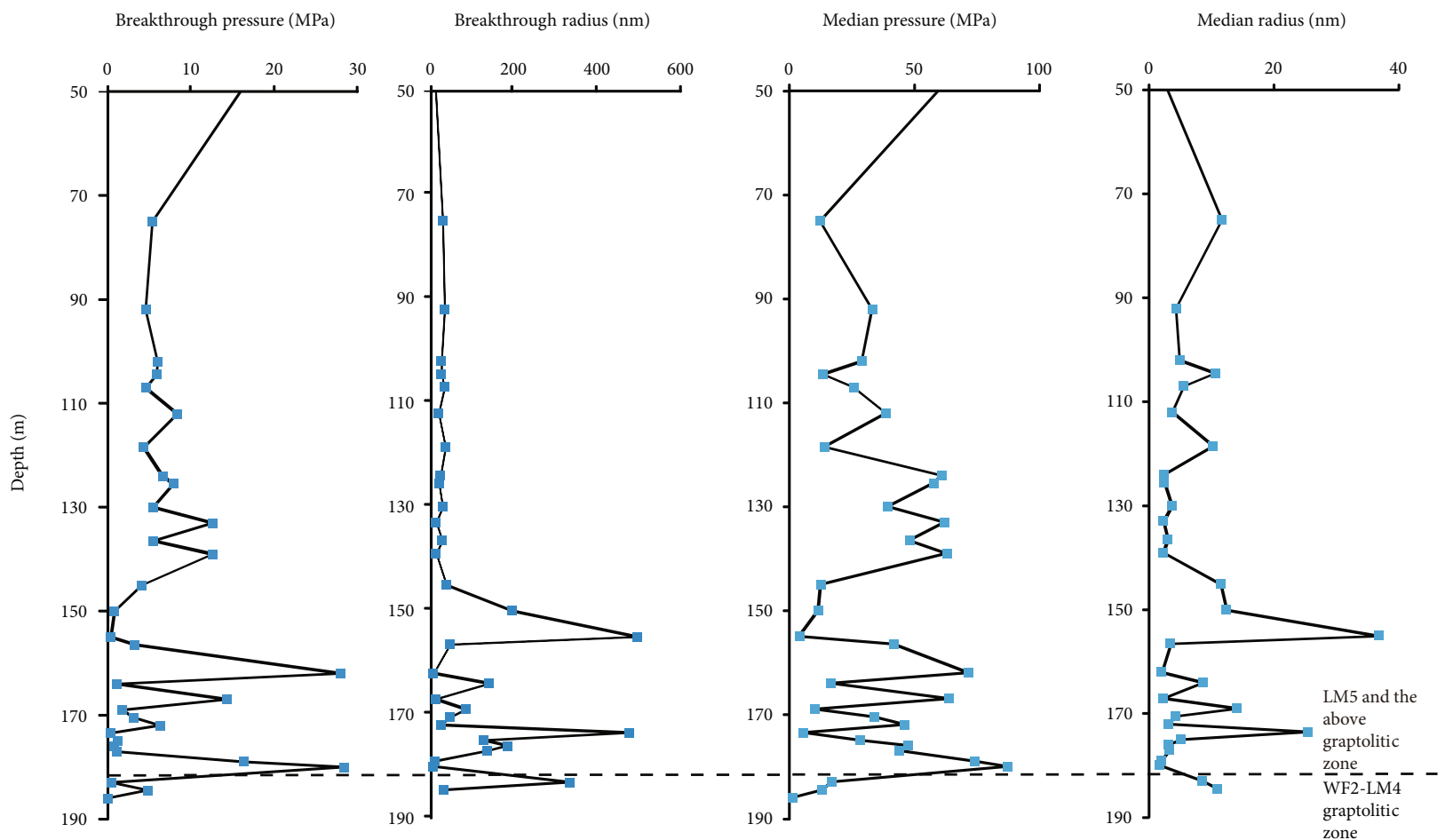

FIGURE 9: The breakthrough pressures, breakthrough radius, median pressures, and median radius (mercury injection capillary pressure data) of the Wufeng and Longmaxi Formations, Guanyinqiao section, Qijiang County, Chongqing Municipality. Because the shale of the outcrop sample is weathered to different degrees, the breakthrough radius and the median radius are large, while the breakthrough pressure and the breakthrough radius are small. However, the overall performance is that the breakthrough pressure and median pressure of the WF2-LM4 GZ is lower than those of the LM5-LM8 GZ, showing the stronger sealing capacity of the LM5-LM8 GZ which is a direct seal for the WF2-LM4 GZ.

source and seal [44]. The LM5-LM8 GZ is the direct seal of the WF2-LM4 GZ (Figure 4).

For shale mineral composition, the quartz content decreases while the clay mineral content increases from the source to seal, the Wufeng Formation to the first member of Longmaxi Formation. With differences in mineralogy, LM5-LM8 GZ is less brittle but more ductile than the WF2LM4 GZ when compacted by equivalent geological stress. Observably high gas content in the WF2-LM4 GZ and a significantly lower one in the LM5-LM6 GZ sequence in the Well JY 1 are shown in Figure 4, indicating that the upper part of the Longmaxi Formation (the LM5-LM6 GZ) served as a direct seal with its much lower porosity and higher clay content preventing shale gas in the WF2-LM4 GZ from escaping.

Furthermore, the capability of direct seals can be quantitatively estimated from breakthrough pressure and median pressure. The breakthrough pressure and median pressure of the WF2-LM4 GZ is lower than those of the LM5-LM8 GZ according to the microscopic pore structure analysis. There is a positive relationship between the breakthrough pressure and the breakthrough radius as well as the median pressure and the median radius indicating that the LM5LM8 GZ plays a role as the direct seal for the WF2-LM4 GZ with its strong sealing capacity [44]. The breakthrough pressure and median pressure, together with the breakthrough radius and median pressure between WF2-LM4
GZ and LM5-LM8 GZ of the Guanyinqiao section in Qijiang County, Chongqing City, have similar characteristics to Well JY 2, that is, the LM5-LM8 GZ is the direct seal for the WF2LM4 GZ (Figure 9).

\section{Coevolutionary Processes and Mechanisms of Shale Hydrocarbon Generation and Reservoir Preservation}

7.1. Source and Reservoir Evolution. Different GZs represent different deposition environments, and this is also true for corresponding hydrocarbon-generating organism assemblages and mineral compositions [19, 39]. Combined, these lead to the differences observed in the interrelationships and coevolution of hydrocarbon generation and reservoir formation processes.

(1) The shale of the WF2-LM4 GZ is siliciclasticdominated featuring a slow deposition rate, favorable organism types (i.e., multicellular algae), high TOC, and high hydrocarbon generation capacity. All of these are then favorable conditions for the further generation, accumulation, and preservation of shale gas. The timing sequence of hydrocarbon generation and reservoir evolution in the WF2-LM4 GZ exhibits signs of a siliceous grid that was formed early and oil 
WF2-LM4 graptolitic zone

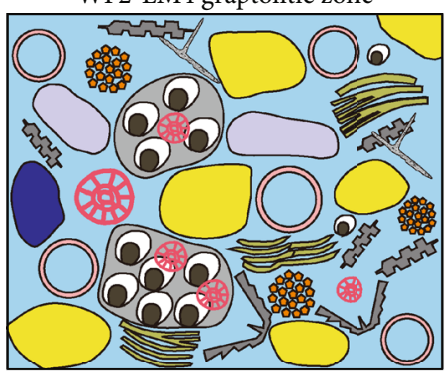

(a)

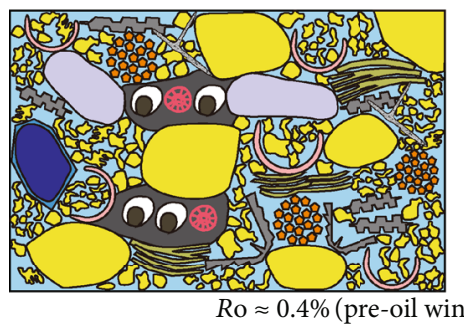

(b)

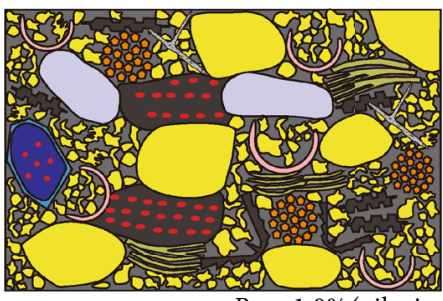

$R o \approx 1.0 \%$ (oil window, depth:2000-3000 m)

(c)

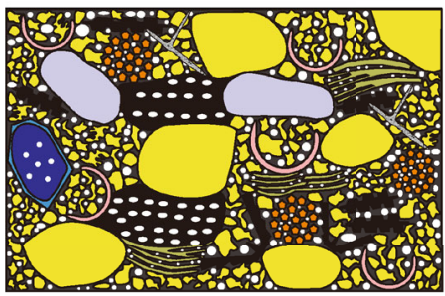

Ro $>1.5 \%$ (gas window, depth $>5000 \mathrm{~m}$ )
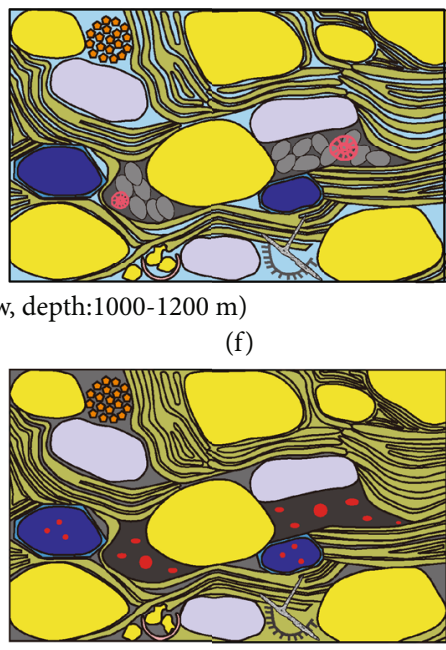

(g)

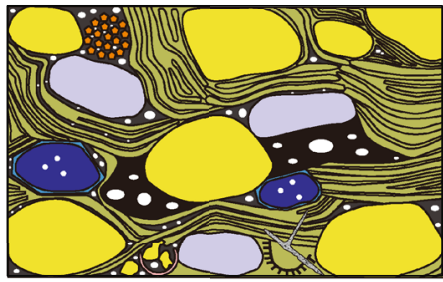

(h)

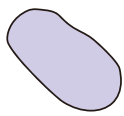

Feldspar
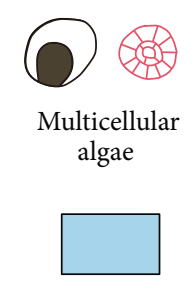

Primary pore

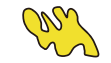

Authigenic quartz

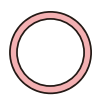

Radiolarian

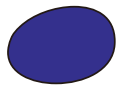

Calcite

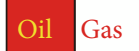

Secondary pore
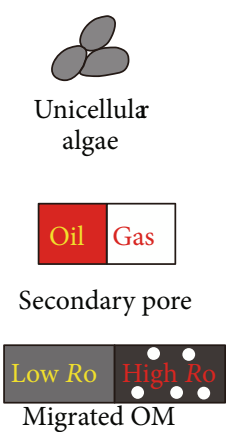

Unicellul

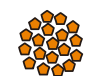

Pyrite

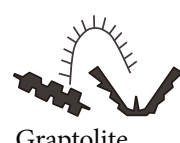

Figure 10: The coevolution processes of the reservoir (WF2-LM4 GZ) and the seal (LM5-LM8 GZ). 
TABLE 1: Comparison of coevolutionary characteristics of between WF2-LM4 GZ and LM5-LM8 GZ in Wufeng Formation to the lower part of the first member of Longmaxi Formation, Sichuan Basin.

\begin{tabular}{|c|c|c|c|}
\hline & Graptolitic zone & LM5-LM8 & WF2-LM4 \\
\hline \multirow{3}{*}{$\begin{array}{l}\text { Source } \\
\text { rock }\end{array}$} & $\begin{array}{l}\text { Hydrocarbon } \\
\text { generation } \\
\text { organisms }\end{array}$ & Green algae, cyanobacteria, and other benthic algae & Red algae, brown algae, and other planktonic algae \\
\hline & TOC (\%) & $<3$ (low) & $>3$ (high) \\
\hline & $\begin{array}{l}\text { Hydrocarbon } \\
\text { generating capacity }\end{array}$ & Weak & Strong \\
\hline \multirow{3}{*}{$\begin{array}{l}\text { Reservoir } \\
\text { rock }\end{array}$} & Quartz & Mainly terrigenous silica & Mainly biogenic silica \\
\hline & Pore types & Dominated by mineral pores, few & Dominated by organic matter pore \\
\hline & Porosity (\%) & $<4$ (low) & $>4$ (high) \\
\hline \multicolumn{2}{|c|}{ Source and reservoir evolution } & $\begin{array}{l}\text { Strong ability to form a rigid grid and strong } \\
\text { anticompaction ability; high degree of coevolution }\end{array}$ & $\begin{array}{l}\text { Weak ability to form a rigid grid and strong } \\
\text { anticompaction ability; low degree of coevolution }\end{array}$ \\
\hline \multicolumn{2}{|c|}{ Source and seal evolution } & Usually as the direct seal for shale gas reservoir & Promising shale gas interval \\
\hline
\end{tabular}

that was charged late. The oil generation and corresponding overpressure are beneficial to the development of a shale gas reservoir. The main features are as follows (Figure 10) (Table 1):

(a) Quartz cement in the WF2-LM4 GZ may originate from various silica sources, such as biogenic authigenic silica, mineral transformations, and redistribution (pressure dissolution/clay-induced dissolution) [57]. Assessing the relative contributions of these potential silica sources would require the determination of the relative timing of the authigenic quartz [52]. Understanding the formation of biogenic quartz cement is of great importance for shale gas reservoir evaluation, especially when the formation time of three-dimensional connected frameworks of biogenic silicon is earlier than that of the maximum oil generation, which can provide storage spaces for holding a large amount of oil.

Most of the quartz in the WF2-LM4 GZ is biogenic, which may originate from the dissolution and recrystallization of biogenic silica [44]. The documented temperatures and porosities in effect during the alteration of former biogenic opal-A through the transformation to opal-CT and eventually to microcrystalline quartz $[52,54,61,62]$ are consistent with the observed burial histories. The transformation from opal-A to crystalline microcrystalline quartz has well-documented impacts on the generation of brittle behavior in mudstones [61]. Unconfined compressive strength (UCS) exhibits an abrupt increase from several $\mathrm{MPa}$ above $1000 \mathrm{~m}$ to several tens of $\mathrm{MPa}$ at a depth of $\sim 1000 \mathrm{~m}$, where the silica is opalCT, and the UCS remains at high values at depths of 1000-1200 m; although displaying a gradual decline over this depth range, the UCS is still 10$15 \mathrm{MPa}$ below the depth of $1200 \mathrm{~m}$ [61]. The results show that when the buried depth of shale is at least $1000-1200 \mathrm{~m}$, the silica is opal-CT and the shale has strong brittleness. According to the evolution history of opal-A $\rightarrow$ opal-CT $\rightarrow$ quartz, oxygen isotope analysis shows that the temperature of opal-CT that evolved into quartz-layered flint is $17-21^{\circ} \mathrm{C}[63]$. The thermal maturity is lower than $0.5 \% R_{\mathrm{o}}$ when the temperature is 17 $21^{\circ} \mathrm{C}$ and the burial depth is less than $1000 \mathrm{~m}$, and the formation time for authigenic quartz is Late Early Silurian (early diagenetic stage). Thus, the transformation process seemingly occurred at relatively low temperatures before the oil window. Rapid compaction occurs in response to the gradual increase in burial depth and the infilling of pore spaces in preexisting detrital quartz frameworks with biogenic microcrystalline silica [62].

Intergranular pore space is controlled by the preservation of primary pores [8], which are prone to be preserved under the supporting structure of matrix-dispersed authigenic quartz that prevents compaction [57]. This dissolution and reprecipitation process may transform the siliceous particles in place or reprecipitate dissolved silica in the forms of matrix-dispersed microcrystalline quartz and irregular microcrystalline aggregates in pores that were formed by early detrital quartz [57]. The shape of kerogen particles (hydrocarbon-generating organisms) and the amount of retained oil filled in primary framework pores while relying on the presence of the compaction-resistant rigid grains that are determined by detrital and matrix-dispersed biogenic authigenic quartz for pressure maintenance to preserve porosity. These matrix-dispersed microcrystalline quartz aggregates have an early formation time before the infilling of hydrocarbon compaction occurs. Pore space is abundant enough in microcrystalline quartz aggregates for oil and bitumen filling during the oil window. 
Matrix-dispersed biogenic authigenic quartz occurs as the cement in the primary, irregular, intergranular, and intragranular pores; restrains the compaction; and preserves the internal pore structure together with the detrital quartz as a rigid and three-dimensional framework. This then strengthens the framework and effectively increases the shale brittleness at the same time. The rock matrix formed by high quartz content has a strong ability to resist compaction that provides abundant spaces for maintaining OM, especially for the retention of large amounts of oil. Furthermore, during the hydrocarbon generation window, the organic acids generated can dissolve the unstable minerals $[64,65]$, which also increases the storage spaces. The filling of early oil may have some inhibiting effects on shale diagenesis and slow the compaction process.

(b) The TOC is one of the main controlling factors for hydrocarbon generation. The TOC content is generally high, commonly between $2 \%$ and $5 \%$, and the OM mainly exists in flocculent states in the siliceous particles or between the quartz particles. Organic petrology coupled with backscattered and field emission SEM indicates that the OM type (mainly multicellular algae) is the most significant contributor to the TOC content and $\mathrm{OM}$ porosity, ensuring the matching of gas generation and OM pore development. The thermal simulation experiment results show that the generated oil yield from modern planktonic algae is almost double or triple that of benthic algae [48]. The WF2-LM4 GZ dominated by the multicellular algae had a much higher oil generation potential than the LM5-LM8 GZ where unicellular algae were common. The organic-rich WF2LM4 GZ is favorable to oil generation and adsorption, as well as primary oil expulsion to the intergranular pores of biogenic quartz matrices, bringing in high oil retention in TOC-rich and biogenic quartz-rich graptolitic shales. It is generally assumed that multicellular algae have complex cell structures and a stronger ability to generate multiple kinds of OM pores than unicellular algae during thermal maturation [9]. The OM pores in the multicellular algae are well developed within the algae and inherited the original biological structure [42], the sizes of which are usually hundreds of $\mathrm{nm}$, or even $\mu \mathrm{m}$ scale. Additionally, the TOC content also determines the number of OM pores.

(c) The retention of hydrocarbons in shales of the WF2-LM4 GZ is mainly controlled by the sorption capacity of OM and the spaces in threedimensional connected frameworks of biogenic silica $[19,44]$, in which the oil was retained in absorbed and free states, respectively. A similar retention phenomenon related to the presence of porous fossils exists in the Marathon 1 Mesquite Well [66], where siliceous sponge spicules enhance the storage capacity for bitumen [67]. For gas generation, the secondary cracking of the residual oil is the main source $[1,32,33,68$, 69]. Shale gas content is largely determined by the amount of residual oil cracking during high thermal maturity in organic-rich shales $[69,70]$. The WF2-LM4 GZ has high content of TOC and silica that is associated with multicellular algae [37]. During the oil window, the generated oil was filled in kerogen and/or expelled from the kerogen and migrated into the adjacent interparticle and intraparticle mineral pores. With increasing maturity, the normalized concentration of retained oil (S1/TOC.100) TOC increased in the oil window [67]. During the stage of oil cracking, the generation of gas, the formation of OM pores, and overpressure coevolved to offset the effects of compaction. In particular, the residual oil and overpressure have important effects on reservoir formation, which are conducive to the development and preservation of OM pores.

However, with increasing maturity, the cracking and releasing of bulk labile hydrocarbon moieties from kerogen structures might likely leave behind a more rigid and aromatic kerogen residue $[67,71]$, while the residual oil similarly leaves behind a more rigid and aromatic bitumen. Therefore, the formation of OM pores is most likely a result of the release of massive amounts of hydrocarbons $[19,67]$. The abundance of $\mathrm{OM}$ pores and degree of connectivity in the three-dimensional OM pore network synergistically increased with an increasing authigenic quartz content in the WF2-LM4 GZ. Residual oil principally fills into the aggregates of authigenic microcrystalline pore networks with the deposition $\mathrm{OM}$ and would be likely to generate a better connected three-dimensional OM pore network through secondary cracking, which provides favorable storage space for shale gas in shales of the WF2-LM4 GZ.

To summarize the results above, a logical conclusion is that the coevolution of high contents of favorable $\mathrm{OM}$ and quartz (multicellular algae and biogenic quartz) provided high hydrocarbon generation potential and connected threedimensional networks that may have resulted in the retention of large amounts of oil and kerogen in the rigid interparticle and intraparticle mineral pores. During the stage of oil cracking, the generation of gas and overpressure coevolved to produce an environment conducive to the development and preservation of OM pores and 
to offset compaction. In particular, the WF2LM4 GZ offers a promising reservoir with favorable types and characteristics that are the result of multifactor coupling and coevolution. Reservoir potential should thus not be viewed as being determined by a single factor, but rather as the synergy among many factors, such as hydrocarbon generation potential, porosity, TOC, and quartz contents.

(2) The shale of the LM5-LM8 GZ are clay-dominated and characterized by a fast deposition rate, unfavorable organic organism type (mainly unicellular algae), low TOC, and low hydrocarbon generation capacity, all of which are not favorable conditions for the generation, accumulation, and preservation of shale gas. The timing sequence of hydrocarbon generation and reservoir evolution of the LM5-LM8 GZ experienced early densification of the reservoir and oil that was charged late; the main features are as follows:

(a) The siliceous minerals of the LM5-LM8 GZ are mainly terrigenous and detrital in origin with trace amounts of biogenic authigenic quartz [19]. The clay mineral content is higher than that of WF2LM4 GZ. The most unfavorable factor is that the compaction resistance ability of these terrestrial detrital silica and clay minerals is weak and cannot form well-connected three-dimensional frameworks. The radiolarians and sponge spicules slowly gathered and dissolved due to the high deposition rate. Furthermore, the precipitation amount of biogenic authigenic quartz is also low. Without this support, the framework of terrigenous siliciclastic silica with high clay content collapses easily during strong compaction. This densification of the shale reservoir and the reduced porosity and permeability limit the storage space for the retention of oil and migrated $\mathrm{OM}$ patches. The transforming period of quartz produced during clay transformation was consistent with the oil generation window that further reduced the pores for the retention of oil and migrated OM patches $[57,72]$.

(b) The hydrocarbon-generating organisms of the LM5-LM8 GZ were mainly unicellular algae, with lower TOC content. The pores in unicellular algae are developed by the arrangement gaps of unicellular algae, in which the size is tens to greater than one hundred $\mathrm{nm}$ [42]. These two factors led to a poor hydrocarbon generation ability, fewer OM pores, isolated pore distribution, and an inability to form an interconnected three-dimensional OM pore system, all of which is unfavorable to the enrichment and production of shale gas.

(c) The amount of natural gas generation in the LM5-LM8 GZ largely depends upon the amount of retained oil generated by authigenic $\mathrm{OM}$ and the oil that may be migrated from the WF2LM4 GZ. Due to the small amount of selfgenerated oil and pores for oil retention, the storage space for natural gas was limited during the oil cracking stage. Additionally, both the kerogen and the residual oil have low capacities to generate gas that make it difficult to form OM networks when there is little to no biogenic authigenic quartz present. In this case, only trace amounts of an OM network exist in the LM5LM8 GZ.

7.2. Source and Seal Evolution. A good match between the shale gas generation from an organic-rich shale source and the development of the direct seal is critical for the assessment of shale gas enrichment in the Sichuan Basin, South China. The pore evolution simulation performed for TOC and mineral compositions of the WF2-LM4 GZ and LM5LM8 zones in Well JY 1 showed that the porosity of OM pores in the WF2-LM4 GZ increased at a greater burial depth with the thermal maturity of $0.6 \%$, while the porosity of the mineral pores gradually decreased with evolution. The Middle Cretaceous was the peak period for dry gas generation and OM pore formation in the WF2-LM4 GZ. Yet in the LM5-LM8 GZ, the mineral pores are dominant and with little OM pores. The porosity of the LM5-LM8 GZ decreased due to the lack of supplement to increase OM pores during the overmature dry gas generation window, ranging from $3.19 \%$ to $5.09 \%$ (Figure 11). The WF2-LM4 GZ is the source and reservoir for shale gas with its high TOC high residual oil content and OM-hosted porosity, while the overlying LM5LM8 GZ is the direct cap rock.

The shape of porosity-decline curves is defined by initial porosity, grain size, and mineral composition [58]. In short, they are governed by the microfabric [73], and the microfabric, in turn, controls the reservoir types and characteristics. To obtain the evolution of porosity of the two GZ, the burial history reconstruction and the thermal history simulation were performed, revealing the differences between the source (WF2-LM4 GZ) and the direct seal (LM5-LM8 GZ). The porosity of mineral pores in the WF2-LM4 GZ exhibited a decreasing trend with burial depth, dropping to a minimum value of $1.0 \%$ to $1.5 \%$ in the Middle Cretaceous. Then, the porosity of mineral pores presented a slight increase accompanying the uplift, reaching $\sim 2.0 \%$ to the recent. On the other hand, the porosity of OM pores in the WF2-LM4 GZ showed an obvious increase during the Early Triassic when the thermal maturity reached $0.6 \% R_{\mathrm{o}}$, reaching $2.5 \%$ in the EarlyMiddle Cretaceous. Since then, under the decompression during the uplift, it has slightly increased to $\sim 3.0 \%$ till the present. The average total porosity is about $6 \%$ in the WF2-LM4 GZ, much greater than that in the LM5-LM8 GZ (Figure 11). The porosity of the OM pores is about $1 \%$ in the LM5-LM8 GZ. Thus, the LM5-LM8 GZ can be regarded as a direct seal for the shale gas reservoir in the WF2-LM4 GZ. In conclusion, the source rock and direct seal form a strong coevolutionary matching, favorable for shale gas accumulation. 


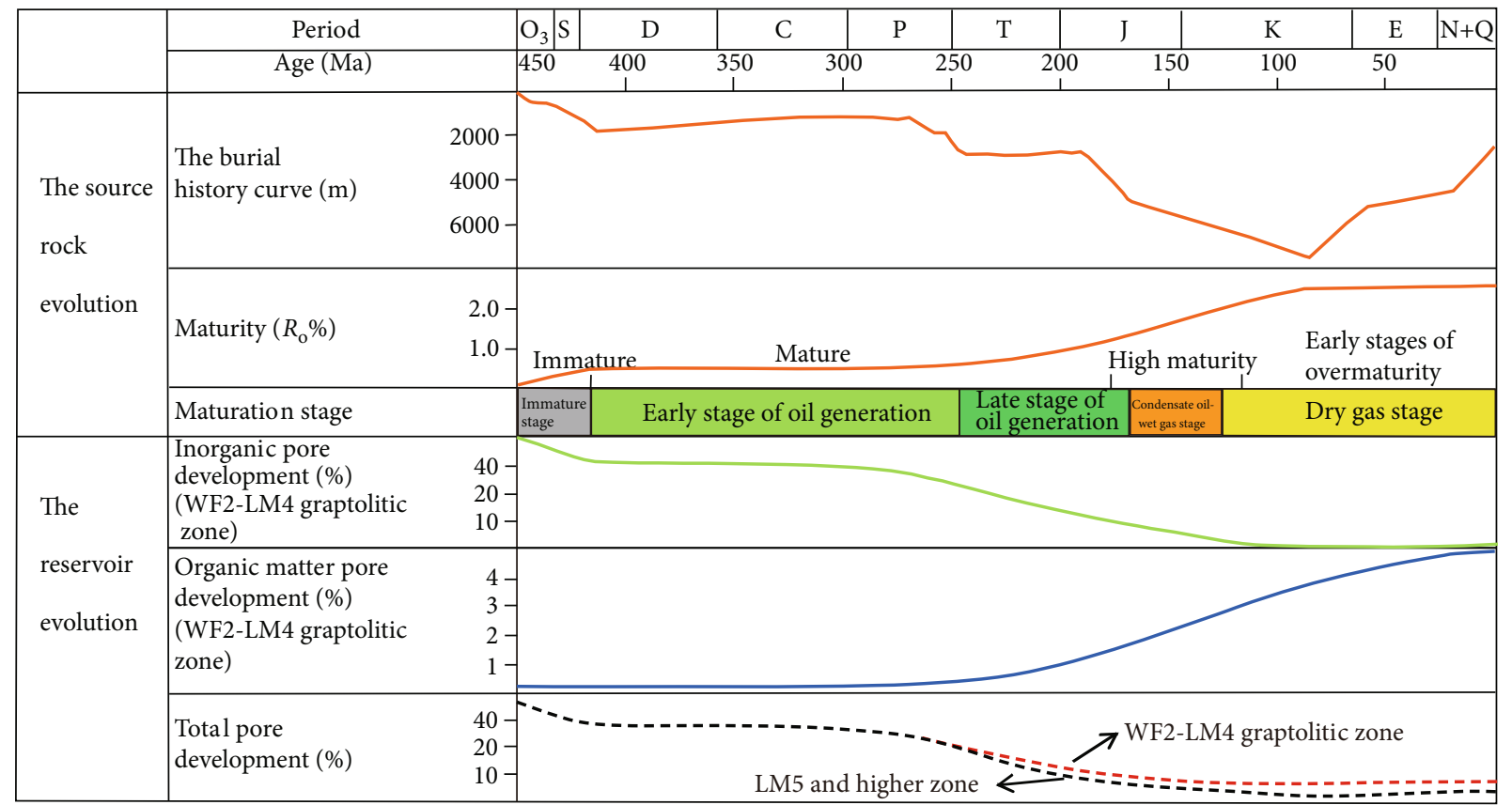

FIgURE 11: Porosity evolution history of the Wufeng and Longmaxi Formation shale gas reservoir in the Jiaoshiba area (modified from [20]).

7.3. Evolution of the Source, Reservoir, and Preservation. Based on the burial history of Well JY 1, the black shale in the Wufeng and Longmaxi Formations underwent four stages of evolution of the source, reservoir, and preservation (Figure 7):

(1) In the Early Devonian, an initial stage of rapid subsidence and burial occurred during which only a small amount of heavy oil was generated. With the small amounts of detrital quartz, the matrixdispersed biogenic authigenic quartz in the WF2LM4 GZ occurs as the cement in primary anomalous intergranular and intragranular pores that restrained the compaction to preserve the pore structure as rigid and connected threedimensional frameworks strengthened the rock framework and increased the shale brittleness effectively at the same time. Without the support of biogenic silica, the framework of terrigenous siliciclastic silicon with high clay content collapses easily during compaction, which results in smaller storage spaces for retaining oil and migrated OM patches.

(2) The second stage of subsidence occurred in the EarlyMiddle Triassic. A large amount of oil might remain in the shales of the WF2-LM4 GZ because of a rapid, limited-amplitude uplift and a low oil expulsion efficiency. Existing biogenic authigenic quartzsupported three-dimensional framework porosity is filled with migrating hydrocarbons and subsequently results in the development of OM micropores in those places. During this period, the direct seal rock was formed when the shale reached high maturity at $\sim 1.2 \% R_{\mathrm{o}}$.
(3) The third stage of subsidence extended from the Early Jurassic to Middle Cretaceous. The kerogen and residual oil can generate a great amount of gas and bitumen through cracking, also resulting in large amounts of OM pores for gas storage when the shale reached maximum maturity. Meanwhile, this time was the most productive gas generation period for the WF2-LM4 GZ, that is, peak gas generation and formation of massive OM pores were synchronous. However, the porosity of the LM5-LM8 GZ was at its minimum in this period. During the periods of largest gas generation, OM pore formation, seal formation of direct cap rocks overlapped and formed a strong matching for shale gas accumulation and preservation in the Wufeng and Longmaxi Formations (Figures 7 and 11). Meanwhile, the regional seal of the Lower Triassic gypsum layer was formed during the Late Jurassic-Early Cretaceous [74], before the periods of greatest gas generation and $\mathrm{OM}$ pore formation.

(4) The acceleration of the uplift stage from the middle stage of the Late Cretaceous led to the cease of the hydrocarbon generation process and diagenesis process resulting from the thermal maturation evolution. Besides, pores in the minerals resulting from the decompression process turn larger, the organic pores increase to different degrees, and the preexisting fissures reopen [11]. If the tectonic uplift is too strong, the large and deep faults would develop in the shale and exodiagenesis could occur with freshwater pouring into fractures. And all kinds of dissolution processes of inorganic minerals would do great damage to the shale gas reservoir. What is more, the organic 
diagenesis and organic-inorganic interaction process turn relatively weak.

It should be noted that the research of coevolutionary dynamics of organic-inorganic interactions, hydrocarbon generation, and shale gas reservoir preservation of the Upper Ordovician Wufeng and Lower Silurian Longmaxi Formations between the WF2-LM4 GZ and the LM5-LM8 GZ is a theoretical study of the static characteristics, coevolution process, evolution mode, and evolution characteristics of two graptolite zones. However, these are controlled by the black shale depositional environment, the tectonic evolution experienced by the shale strata after deposition, and the current structural location, type, and characteristic. The shale gas reservoir characteristics and shale gas enrichment characteristics of different graptolite zones may not be completely consistent with theoretical models, and specific analysis needs to be combined with the sedimentary environment and structural background in the study area. Taking the Upper Ordovician Wufeng and Lower Silurian Longmaxi Formations in the Sichuan Basin and its surrounding areas as an example, it is necessary to determine the thickness and sequence evolution characteristics of the WF2-LM4 GZ based on the shale depositional environment, structural background, and exploration and development costs. To further predict the shale gas enrichment area, mapping the WF2-LM4 GZ will be a major task in future exploration and a lot of work needs to be carried out.

\section{Analysis of Wufeng and Longmaxi Shale Gas Potential}

8.1. The Coevolution Processes between the WF2-LM4 GZ and the LM5-LM8 GZ. Since the hydrocarbon-generating organisms of the WF2-LM4 GZ are mainly multicellular algae that have high TOC content and a high hydrocarbon-generating capacity, the organic acids generated are greater than those of the LM5-LM8 GZ. The generated organic acids preferentially dissolve the unstable minerals in the shale and typically chemically react with feldspar particles to precipitate kaolinite and microcrystalline quartz [75]. The dissolution of unstable minerals further reinforces and preserves the connected three-dimensional framework spaces of biogenic silica formed before the organic acid formation, which is favorable for oil retention in the shale of the WF2-LM4 GZ. Strongly coupled with the large amounts of oil generation that is determined by the multicellular algae, the kerogen and the biogenic silica-connected three-dimensional frameworks can retain much oil, which greatly determines the gas content in shale by generating cracking gas and porous pyrobitumen at high thermal maturities. Previous reports on adsorbed oil in kerogen proposed that $170 \mathrm{mg} / \mathrm{g}$ TOC can contribute to $\sim 22 \%$ of free oil, estimating that shale has great potential for oil generation [69]. This constitutes a large portion of the retained oil in shales. All of these favorable factors (i.e., favorable OM type and TOC content, the formation of connected three-dimensional networks of biogenic authigenic quartz before oil charge, and overlapped generation periods of natural gas, OM pores, and overpressure) suggest a high level of source-reservoir coevolution to provide ideal conditions for shale gas accumulation.

Because of the lack of biogenic silica needed to form connected three-dimensional frameworks in the LM5-LM8 GZ, the dissolution of unstable minerals by organic acids and the precipitation of microcrystalline quartz transformed by clay minerals strengthened the compaction and further reduced the porosity. The storage space for oil is smaller than in the WF2-LM4 GZ. By the coupling of a low oil generation potential (driven by unicellular algae) and small storage spaces for oil retention, a small amount of gas may be hosted in various pores and dominantly in the mineral pores, which reveals a low level of source-reservoir coevolution.

The two coevolution processes are conducive to a high spatiotemporal matching of the reservoir (WF2-LM4 GZ) and seal (LM5-LM8 GZ) due to their different coevolving processes of gas generation, OM pore formation, and direct seal formation.

Shale gas displays the feature of being a self-sourced and self-accumulating reservoir and mixes by the cracking gases of oil and kerogen at high maturity $[1,2,76]$. The WF2LM4 GZ is the source and reservoir with favorable accumulation conditions for shale gas development, characterizing a slow deposition rate, favorable organism type, high TOC and high hydrocarbon generation capacity, high quartz content, and high degree of coevolution between hydrocarbon generation and the reservoir $[19,20]$. At present, the WF2LM4 GZ is the main prospect section of exploration, and three national shale gas exploration areas in the Fuling, Weiyuan, Changning, and Zhaotong, have been constructed where the thickness of the WF2-LM4 GZ is over $20-25 \mathrm{~m}$ [20]. The WF2-LM4 GZ is the most profitable GZ for shale gas accumulation, and it displays excellent exploration potentials. Even outside the Sichuan Basin where the tectonics are relatively strong, the WF2-LM4 GZ can also form good normal pressure shale gas reservoirs $[77,78]$.

8.2. The Shale Gas Exploration Potential of the LM5-LM8 GZ. Shale gas exploration also exhibits generally unsatisfactory production from the shale in the LM5-LM8 GZ except where structural highs have enhanced hydrocarbon accumulation [79]. The LM5-LM8 GZ directly overlaps the high-quality source rocks of the WF2-LM4 GZ, and the local poredeveloped areas typically have a good ability to store oil and maybe reservoirs for migrated oil. During the oil cracking stage, the oil will crack to natural gas to form porous bitumen and store the locally generated shale gas. There may also be some natural gas migrated from the WF2-LM4 GZ. The LM5-LM8 GZ may also have shale gas accumulation which has been confirmed by exploration [80]. The JY 11-2-1HF Well and JY 29-S1 Well are located at the apex and the slope of the Jiaoshi box-shaped anticline, respectively, and the depths of the targets are $2200 \mathrm{~m}$ and $2400 \mathrm{~m}$, respectively. In June of 2015, the JY 11-2-1HF Well operated by Sinopec reached a test production of $287,000 \mathrm{~m}^{3} / \mathrm{d}$ after hydraulic fracturing (the horizontal interval only has a length of $780 \mathrm{~m}$ ), which is a strategic milestone in the LM5-LM8 GZ. However, the JY 29-S1 Well reached a test production of $248,000 \mathrm{~m}^{3} / \mathrm{d}$ after the hydraulic fracturing (the horizontal 
interval has a length of $1502 \mathrm{~m}$ ). The horizontal interval of the JY 29-S1 Well is almost twice that of the JY 11-2-1HF Well, but the test production is nearly identical. The permeter production of the JY 11-2-1HF Well is thus twice that of the JY 29-S1 Well. It is believed that there may be a primary migration in the LM5-LM8 GZ, resulting in a high degree of shale gas enrichment in the upper part of the Jiaoshiba anticline $[79,80]$. It is suggested that the development of LM5-LM8 GZ should start from the high part of the structure and gradually expand to the low part.

\section{Conclusions}

In our study, the Fuling $\mathrm{O}_{3} w-\mathrm{S}_{1} l$ Shale Gas Field in the eastern Sichuan Basin was used as a case study to discuss the coevolutionary processes and organic-inorganic interactions of hydrocarbon generation and reservoir preservation. This comprehensive analysis revealed that the dynamics of organic-inorganic interactions and coevolution in hydrocarbon generation and reservoir preservation are quite different among shale GZs in terms of hydrocarbon generation, types, and characteristics of shale gas reservoirs; seal characteristics; and their spatiotemporal relationships.

The WF2-LM4 GZ contains planktonic algae featuring the majority of multicellular algae, high TOC, strong hydrocarbon generation capacity, and a high-quality shale gas reservoir with connected OM pore networks. Taken together, all of these result in favorable conditions for the development of a high degree of coevolution in hydrocarbon generation and accumulation. The high degree of coupling among favorable $\mathrm{OM}$, biogenic authigenic quartz, and organic-inorganic interactions likely led to coevolution and the favorable conditions for shale gas accumulation.

However, the overlying LM5-LM8 GZ exhibits signs of early densification and late charge and has a reverse mode of reservoir development. This is likely due to the lack of biogenic microcrystalline opal-CT/quartz precipitation to preserve and reinforce the preexisting framework, together with the unfavorable matching between oil generation and pore development, which cannot provide enough storage spaces for oil retention to generate widespread cracking gas and $\mathrm{OM}$ pores during the high maturation window.

These two coevolutionary processes are conducive to a high degree of spatiotemporal matching between the reservoir (i.e., WF2-LM4 GZ) and the seal (i.e., LM5-LM8 GZ). This may be due to their different coevolutionary histories of gas generation, OM pore formation, and direct seal formation, which laid the foundation for the coevolutionary dynamics of hydrocarbon generation and reservoir preservation.

We believe that our comprehensive research and the mechanisms formulated for the coevolution of organicinorganic interactions and hydrocarbon generation and reservoir preservation have determined that the WF2-LM4 GZ is the most promising interval for shale gas exploration and development in the Sichuan Basin. Furthermore, the insights provided here may be used as a framework for the geological theory, exploration, and development of shale gas worldwide.

\section{Data Availability}

The data that support the findings of this study are available from the corresponding author upon reasonable request.

\section{Conflicts of Interest}

The authors declare no conflicts of interest.

\section{Acknowledgments}

The study was supported by the China National Natural Science Foundation (Grant No. 41872124) and Sinopec inhouse projects. We are grateful for Sinopec Petroleum Exploration and the Development Research Institute, Sinopec Jianghan Oilfield and Sinopec Exploration Company, for the valuable data provided. We thank Xu Chen, Juanxuan Fan, and Qing Chen for their support in graptolite identification and data collection. We also thank Sinopec management for permission to publish this work.

\section{References}

[1] J. B. Curtis, "Fractured shale-gas systems," AAPG Bulletin, vol. 86, no. 11, pp. 1921-1938, 2002.

[2] J. C. Zhang, Z. J. Jin, and M. S. Yuan, "Reservoiring mechanism of shale gas and its distribution," Natural Gas Industry, vol. 24, no. 7, pp. 15-18, 2004.

[3] R. G. Loucks and S. C. Ruppel, "Mississippian Barnett shale: lithofacies and depositional setting of a deep-water shale-gas succession in the Fort Worth Basin, Texas," AAPG Bulletin, vol. 91, no. 4, pp. 579-601, 2007.

[4] R. G. Loucks, R. M. Reed, S. C. Ruppel, and D. M. Jarvie, "Morphology, genesis, and distribution of nanometer-scale pores in siliceous mudstones of the Mississippian Barnett shale," Journal of Sedimentary Research, vol. 79, no. 12, pp. 848-861, 2009.

[5] G. R. Chalmers, R. M. Bustin, and I. M. Power, "Characterization of gas shale pore systems by porosimetry, pycnometry, surface area, and field emission scanning electron microscopy/transmission electron microscopy image analyses: examples from the Barnett, Woodford, Haynesville, Marcellus, and Doig units," AAPG Bulletin, vol. 96, no. 6, pp. 10991119, 2012.

[6] M. E. Curtis, B. J. Cardott, C. H. Sondergeld, and C. S. Rai, "Development of organic porosity in the Woodford shale with increasing thermal maturity," International Journal of Coal Geology, vol. 103, pp. 26-31, 2012.

[7] M. E. Curtis, C. H. Sondergeld, R. J. Ambrose, and C. S. Rai, "Microstructural investigation of gas shales in two and three dimensions using nanometer-scale resolution imaging," AAPG Bulletin, vol. 96, no. 4, pp. 665-677, 2012.

[8] R. G. Loucks, R. M. Reed, S. C. Ruppel, and U. Hammes, "Spectrum of pore types and networks in mudrocks and a descriptive classification for matrix-related mudrock pores," AAPG Bulletin, vol. 96, no. 6, pp. 1071-1098, 2012.

[9] H. K. Nie, R. K. Bian, P. X. Zhang, and B. Gao, "Micro-types and characteristics of shale reservoir of the Lower Paleozoic in Southeast Sichuan Basin, and their effects on the gas content," Earth Science Frontiers, vol. 21, no. 4, pp. 331-343, 2014, in Chinese with English Abstract. 
[10] H. K. Nie, J. C. Zhang, and S. L. Jiang, "Types and characteristics of the lower Silurian shale gas reservoirs in and around the Sichuan basin," Acta Geologica Sinica(English Edition), vol. 89, no. 6, pp. 1973-1985, 2015.

[11] Z. L. He, H. K. Nie, J. H. Zhao, W. Liu, F. Bao, and W. T. Zhang, "Types and origin of nanoscale pores and fractures in Wufeng and Longmaxi shale in Sichuan basin and its periphery," Journal of Nanoscience and Nanotechnology, vol. 17, no. 9, pp. 6626-6633, 2017.

[12] R. M. Slatt and N. R. O'Brien, "Pore types in the Barnett and Woodford gas shales: contribution to understanding gas storage and migration pathways in fine-grained rocks," AAPG Bulletin, vol. 95, no. 12, pp. 2017-2030, 2011.

[13] K. L. Milliken, M. Rudnicki, D. N. Awwiller, and T. Zhang, "Organic matter-hosted pore system, Marcellus formation (Devonian), Pennsylvania," AAPG Bulletin, vol. 97, no. 2, pp. 177-200, 2013.

[14] R. G. Loucks and R. M. Reed, "Scanning-electron-microscope petrographic evidence for distinguishing organic matter pores associated with depositional organic matter versus migrated organic matter in mudrocks," Gcags Transactions, vol. 3, pp. 51-60, 2014.

[15] M.-F. Romero-Sarmiento, J.-N. Rouzaud, S. Bernard, D. Deldicque, M. Thomas, and R. Littke, "Evolution of Barnett shale organic carbon structure and nanostructure with increasing maturation," Organic Geochemistry, vol. 71, pp. 716, 2014.

[16] S. C. Löhr, E. T. Baruch, P. A. Hall, and M. J. Kennedy, "Is organic pore development in gas shales influenced by the primary porosity and structure of thermally immature organic matter?," Organic Geochemistry, vol. 87, pp. 119-132, 2015.

[17] M. Pommer and K. Milliken, "Pore types and pore-size distributions across thermal maturity, Eagle Ford Formation, southern Texas," AAPG Bulletin, vol. 99, no. 9, pp. 1713-1744, 2015.

[18] W. M. Ji, Y. Song, Z. H. Rui, M. M. Meng, and H. X. Huang, "Pore characterization of isolated organic matter from high matured gas shale reservoir," International Journal of Coal Geology, vol. 174, pp. 31-40, 2017.

[19] H. K. Nie and Z. J. Jin, "Source rock and cap rock controls on the upper Ordovician Wufeng formation-lower Silurian Longmaxi formation shale gas accumulation in the Sichuan basin and its peripheral areas," Acta Geologica Sinica(English Edition), vol. 90, no. 3, pp. 1059-1060, 2016.

[20] Z. J. Jin, H. K. Nie, Q. Y. Liu, J. H. Zhao, and T. Jiang, "Source and seal coupling mechanism for shale gas enrichment in upper Ordovician Wufeng formation - lower Silurian Longmaxi formation in Sichuan basin and its periphery," Marine and Petroleum Geology, vol. 97, pp. 78-93, 2018.

[21] M. Mastalerz, A. Schimmelmann, A. Drobniak, and Y. Chen, "Porosity of Devonian and Mississippian New Albany shale across a maturation gradient: insights from organic petrology, gas adsorption, and mercury intrusion," AAPG Bulletin, vol. 97, no. 10, pp. 1621-1643, 2013.

[22] Q. Chen, J. C. Zhang, X. Tang, W. J. Li, and Z. M. Li, "Relationship between pore type and pore size of marine shale: an example from the Sinian-Cambrian formation, upper Yangtze region, South China," International Journal of Coal Geology, vol. 158, pp. 13-28, 2016.

[23] C. H. Ou, C. C. Li, Z. H. Rui, and Q. Ma, "Lithofacies distribution and gas-controlling characteristics of the Wufeng-Longmaxi black shales in the southeastern region of the Sichuan basin, China," Journal of Petroleum Science and Engineering, vol. 165, pp. 269-283, 2018.

[24] R. C. Surdam, L. J. Crossey, E. S. Hagen, and H. P. Heasler, "Organic-inorganic and sandstone diagenesis," AAPG Bulletin, vol. 73, no. 1, pp. 1-23, 1989.

[25] E. A. Prochnow, M. V. D. Remus, J. M. Ketzer, J. C. R. Gouvea, R. Schiffer de Souza, and L. F. De Ros, "Organic - inorganic interactions in oilfield sandstones: examples from turbidite reservoirs in the Campos Basin, offshore eastern Brazil," Journal of Petroleum Geology, vol. 29, no. 4, pp. 361-380, 2006.

[26] R. Weibel, H. Friis, A. M. Kazerouni, J. B. Svendsen, J. Stokkendal, and M. L. K. Poulsen, "Development of early diagenetic silica and quartz morphologies - examples from the Siri Canyon, Danish North Sea," Sedimentary Geology, vol. 228, no. 3-4, pp. 151-170, 2010.

[27] M. Wilkinson and R. S. Haszeldine, "Oil charge preserves exceptional porosity in deeply buried, overpressured, sandstones: Central North Sea, UK," Journal of the Geological Society, vol. 168, no. 6, pp. 1285-1295, 2011.

[28] Z. H. Rui, K. H. Cui, X. Q. Wang et al., "A quantitative framework for evaluating unconventional well development," Journal of Petroleum Science and Engineering, vol. 166, pp. 900-905, 2018.

[29] H. Bu, P. Yuan, H. Liu et al., "Effects of complexation between organic matter (OM) and clay mineral on OM pyrolysis," Geochimica et Cosmochimica Acta, vol. 212, pp. 1-15, 2017.

[30] K. L. Milliken, W. L. Esch, R. M. Reed, and T. Zhang, "Grain assemblages and strong diagenetic overprinting in siliceous mudrocks, Barnett shale (Mississippian), Fort Worth Basin, Texas," AAPG Bulletin, vol. 96, no. 8, pp. 1553-1578, 2012.

[31] J. H. S. Macquaker, K. G. Taylor, M. Keller, and D. Polya, "Compositional controls on early diagenetic pathways in fine-grained sedimentary rocks: implications for predicting unconventional reservoir attributes of mudstones," AAPG Bulletin, vol. 98, no. 3, pp. 587-603, 2014.

[32] R. J. Hill, E. Zhang, B. J. Katz, and Y. Tang, "Modeling of gas generation from the Barnett shale, Fort Worth Basin, Texas," AAPG Bulletin, vol. 91, no. 4, pp. 501-521, 2007.

[33] J. X. Dai, C. N. Zou, S. M. Liao et al., "Geochemistry of the extremely high thermal maturity Longmaxi shale gas, southern Sichuan Basin," Organic Geochemistry, vol. 74, pp. 3-12, 2014.

[34] R. Yang, S. He, X. Wang, Q. Hu, D. Hu, and J. Yi, "Paleo-ocean redox environments of the upper Ordovician Wufeng and the first member in lower Silurian Longmaxi formations in the Jiaoshiba area, Sichuan Basin," Canadian Journal of Earth Sciences, vol. 53, no. 4, pp. 426-440, 2016.

[35] G. W. Zhang, A. L. Guo, Y. J. Wang et al., "Tectonics of South China continent and its implications," Science China: Earth Sciences, vol. 56, no. 11, pp. 1804-1828, 2013.

[36] Z. L. He, Z. Q. Hu, H. K. Nie, S. J. Li, and J. Xu, "Characterization of shale gas enrichment in the Wufeng formation-Longmaxi formation in the Sichuan basin of China and evaluation of its geological construction-transformation evolution sequence," Journal of Natural Gas Geoscience, vol. 2, no. 1, pp. 1-10, 2017.

[37] H. K. Nie, Z. J. Jin, C. X. Sun, Z. L. He, G. X. Liu, and Q. Y. Liu, "Organic matter types of the Wufeng and Longmaxi formations in the Sichuan basin, South China: implications for the formation of organic matter pores," Energy \& Fuels, vol. 33, no. 9, pp. 8076-8100, 2019.

[38] Z. J. Jin, Z. Q. Hu, B. Gao, and J. H. Zhao, "Controlling factors on the enrichment and high productivity of shale gas in the 
WufengLongmaxi formation, southeastern Sichuan basin," Earth Science Frontiers, vol. 23, no. 1, pp. 1-10, 2016, in Chinese with English Abstract.

[39] X. Chen, J. X. Fan, W. H. Wang et al., "Stage-progressive distribution pattern of the Lungmachi black graptolitic shales from Guizhou to Chongqing, Central China," Science China: Earth Sciences, vol. 60, no. 6, pp. 1133-1146, 2017.

[40] X. Chen, R. Jiayu, C. E. Mitchell et al., "Late Ordovician to earliest Silurian graptolite and brachiopod biozonation from the Yangtze region, South China, with a global correlation," Geological Magazine, vol. 137, no. 6, pp. 623-650, 2000.

[41] J. Fan, M. J. Melchin, X. Chen et al., "Biostratigraphy and geography of the Ordovician-Silurian Lungmachi black shales in South China," Science China Earth Sciences, vol. 54, no. 12, pp. 1854-1863, 2011.

[42] H. K. Nie, Z. J. Jin, and J. C. Zhang, "Characteristics of three organic matter pore types in the Wufeng-Longmaxi shale of the Sichuan basin, Southwest China," Scientific Reports, vol. 8, no. 1, p. 7014, 2018.

[43] H. K. Nie, Z. J. Jin, X. Ma, Z. B. Liu, T. Lin, and Z. H. Yang, "Dispositional characteristics of Ordovician Wufeng formation and Silurian Longmaxi formation in Sichuan basin and its adjacent areas," Petroleum Research, vol. 2, no. 3, pp. 233246, 2017.

[44] Z. J. Jin, M. W. Li, Z. Q. Hu, B. Gao, H. K. Nie, and J. H. Zhao, "Shorten the learning curve through technological innovation: a case study of the Fuling shale gas discovery in Sichuan basin, SW China," in Proceedings of the 3rd Unconventional Resources Technology Conference, pp. 1-13, San Antonio, Texas, USA, 2015.

[45] D. G. Liang, T. L. Guo, J. P. Chen, L. Z. Bian, and Z. Zhao, "Some progresses on studies of hydrocarbon generation and accumulation in marine sedimentary regions, Southern China (part 2)," Marine Origin Petroleum Geology, vol. 14, no. 1, pp. 1-15, 2009, in Chinese with English Abstract.

[46] G. R. L. Chalmers and R. M. Bustin, "A multidisciplinary approach in determining the maceral (kerogen type) and mineralogical composition of Upper Cretaceous Eagle Ford formation: impact on pore development and pore size distribution," International Journal of Coal Geology, vol. 171, pp. 93-110, 2017.

[47] D. G. Liang, T. L. Guo, J. P. Chen, L. Z. Bian, and Z. Zhao, "Some progresses on studies of hydrocarbon generation and accumulation in marine sedimentary regions, Southern China (part 3): controlling factors on the sedimentary facies and development of Palaeozoic marine source rocks," Marine Origin Petroleum Geology, vol. 14, no. 2, pp. 1-19, 2009, in Chinese with English Abstract.

[48] J. Z. Qin, G. L. Tao, L. Z. B. Tenger, X. M. Xie, and X. D. Fu, "Hydrocarbon-forming organisms in excellent marine source rocks in South China," Petroleum Geology \& Experiment, vol. 32, no. 3, pp. 262-269, 2010, in Chinese.

[49] Y. Zhang, Z. He, S. Lu et al., "Characteristics of microorganisms and origin of organic matter in Wufeng formation and Longmaxi formation in Sichuan basin, South China," Marine and Petroleum Geology, vol. 111, pp. 363-374, 2020.

[50] S. L. Montgomery, D. M. Jarvie, K. A. Bowker, and R. M. Pollastro, "Mississippian Barnett Shale, Fort Worth basin, northcentral Texas: gas-shale play with multi-trillion cubic foot potential," AAPG Bulletin, vol. 89, no. 2, pp. 155-175, 2005.

[51] J. Zhao, Z. Jin, Z. Jin, Y. Geng, X. Wen, and C. Yan, “Applying sedimentary geochemical proxies for paleoenvironment inter- pretation of organic-rich shale deposition in the Sichuan basin, China," International Journal of Coal Geology, vol. 163, pp. 5271, 2016.

[52] K. L. Milliken, S. M. Ergene, and A. Ozkan, "Quartz types, authigenic and detrital, in the Upper Cretaceous Eagle Ford formation, South Texas, USA," Sedimentary Geology, vol. 339, pp. 273-288, 2016.

[53] J. Zhao, Z. Jin, Z. Jin et al., "Mineral types and organic matters of the Ordovician-Silurian Wufeng and Longmaxi shale in the Sichuan basin, China: implications for pore systems, diagenetic pathways, and reservoir quality in fine-grained sedimentary rocks," Marine and Petroleum Geology, vol. 86, pp. 655674, 2017.

[54] J. Schieber, D. Krinsley, and R. Lee, "Diagenetic origin of quartz silt in mudstones and implications for silica cycling," Nature, vol. 406, no. 6799, pp. 981-985, 2000.

[55] J. Götze, M. Plötze, and D. Habermann, "Origin, spectral characteristics and practical applications of the cathodoluminescence (CL) of quartz - a review," Mineralogy and Petrology, vol. 71, no. 3-4, pp. 225-250, 2001.

[56] C. Peltonen, Ø. Marcussen, K. Bjørlykke, and J. Jahren, "Clay mineral diagenesis and quartz cementation in mudstones: the effects of smectite to illite reaction on rock properties," Marine and Petroleum Geology, vol. 26, no. 6, pp. 887-898, 2009.

[57] J. Zhao, Z. Jin, Z. Jin, X. Wen, and Y. Geng, “Origin of authigenic quartz in organic-rich shales of the Wufeng and Longmaxi formations in the Sichuan basin, South China: implications for pore evolution," Journal of Natural Gas Science and Engineering, vol. 38, pp. 21-38, 2017.

[58] K. L. Milliken and R. J. Day-Stirrat, "Cementation in mudrocks: brief review with examples from cratonic basin mudrocks. In: Chatellier, J.-Y. (Ed.), critical assessment of shale resource plays," AAPG Memoir, vol. 103, pp. 133-150, 2013.

[59] D. J. K. Ross and R. M. Bustin, "Investigating the use of sedimentary geochemical proxies for paleoenvironment interpretation of thermally mature organic-rich strata: examples from the Devonian-Mississippian shales, Western Canadian sedimentary basin," Chemical Geology, vol. 260, no. 1-2, pp. 1-19, 2009.

[60] L. T. Ko, R. Loucks, S. Ruppel, T. Zhang, and S. Peng, "Origin and characterization of Eagle Ford pore networks in the South Texas Upper Cretaceous shelf," AAPG Bulletin, vol. 101, no. 3, pp. 387-418, 2017.

[61] E. Ishii, H. Sanada, T. Iwatsuki, Y. Sugita, and H. Kurikami, "Mechanical strength of the transition zone at the boundary between opal-A and opal-CT zones in siliceous rocks," Engineering Geology, vol. 122, no. 3-4, pp. 215-221, 2011.

[62] J. Huggett, J. N. Hooker, and J. Cartwright, "Very early diagenesis in a calcareous, organic-rich mudrock from Jordan," Arabian Journal of Geosciences, vol. 10, no. 12, p. 270, 2017.

[63] R. K. Matheney and L. P. Knauth, "New isotopic temperature estimates for early silica diagenesis in bedded cherts," Geology, vol. 21, no. 6, pp. 519-522, 1993.

[64] I. D. Meshri, "On the reactivity of carbonic and organic acids and generation of secondary porosity," The Society of Economic Paleontologists and Mineralogists (SEPM) Special Publications, vol. 28, pp. 123-128, 1986.

[65] K. Bjørlykke and J. Jahren, "Open or closed geochemical systems during diagenesis in sedimentary basins: constraints on mass transfer during diagenesis and the prediction of porosity 
in sandstone and carbonate reservoirs," $A A P G$ Bulletin, vol. 96, no. 12, pp. 2193-2214, 2012.

[66] Y. Han, N. Mahlstedt, and B. Horsfield, "The Barnett shale: compositional fractionation associated with intraformational petroleum migration, retention, and expulsion," AAPG Bulletin, vol. 99, no. 12, pp. 2173-2202, 2015.

[67] Y. J. Han, B. Horsfield, R. Wirth, N. Mahlstedt, and S. Bernard, "Oil retention and porosity evolution in organic-rich shales," AAPG Bulletin, vol. 101, no. 6, pp. 807-827, 2017.

[68] D. M. Jarvie, R. J. Hill, T. E. Ruble, and R. M. Pollastro, "Unconventional shale-gas systems: the Mississippian Barnett shale of north-central Texas as one model for thermogenic shale-gas assessment," AAPG Bulletin, vol. 91, no. 4, pp. 475-499, 2007.

[69] T. Zhang, X. Sun, K. L. Milliken, S. C. Ruppel, and D. Enriquez, "Empirical relationship between gas composition and thermal maturity in Eagle Ford shale, south Texas," AAPG Bulletin, vol. 101, no. 8, pp. 1277-1307, 2017.

[70] T. Zhang, R. Yang, K. L. Milliken, S. C. Ruppel, R. J. Pottorf, and X. Sun, "Chemical and isotopic composition of gases released by crush methods from organic rich mudrocks," Organic Geochemistry, vol. 73, pp. 16-28, 2014.

[71] B. Horsfield, "Practical criteria for classifying kerogens: some observations from pyrolysis-gas chromatography," Geochimica et Cosmochimica Acta, vol. 53, no. 4, pp. 891-901, 1989.

[72] K. Xi, Y. Cao, J. Jahren et al., "Quartz cement and its origin in tight sandstone reservoirs of the Cretaceous Quantou formation in the southern Songliao basin, China," Marine and Petroleum Geology, vol. 66, pp. 748-763, 2015.

[73] B. Velde, "Compaction trends of clay-rich deep sea sediments," Marine Geology, vol. 133, no. 3-4, pp. 193-201, 1996.

[74] Z. J. Jin, Y. S. Yuan, Q. Y. Liu, and Y. J. Wo, "Controls of Late Jurassic-Early Cretaceous tectonic event on source rocks and seals in marine sequences, South China," Science China (Earth Sciences), vol. 56, no. 2, pp. 228-239, 2013.

[75] H. K. Nie, C. X. Sun, G. X. Liu, W. Du, and Z. L. He, "Dissolution pore types of the Wufeng formation and the Longmaxi formation in the Sichuan basin, south China: implications for shale gas enrichment," Marine and Petroleum Geology, vol. 101, no. 3, pp. 243-251, 2019.

[76] Q. Liu, Z. Jin, X. Wang et al., "Distinguishing kerogen and oil cracked shale gas using $\mathrm{H}$, C-isotopic fractionation of alkane gases," Marine and Petroleum Geology, vol. 91, pp. 350-362, 2018.

[77] X. P. He, G. S. He, Y. Q. Gao, P. X. Zhang, S. F. Lu, and J. Y. Wan, "Geological characteristics and enrichment laws of normal-pressure shale gas in the basin-margin transition zone of SE Chongqing," Natural Gas Industry B, vol. 6, no. 4, pp. 333-346, 2019.

[78] H. K. Nie, H. Wang, Z. L. He, R. Y. Wang, P. X. Zhang, and Y. M. Peng, "Formation mechanism, distribution law and exploration prospect of normal pressure shale gas reservoirtake Upper Ordovician Wufeng formation-Lower Silurian Longmaxi formation in Sichuan basin and its periphery as an example," Acta Petrolei Sinica, vol. 40, no. 1, pp. 131-143, 2019, in Chinese with English Abstract.
[79] D. H. Li, G. X. Liu, H. K. Nie, J. G. Hu, G. Chen, and Q. W. Li, "Development characteristics and influencing factors of upper gas reservoir in Jiaoshiba anticline," Earth Science-Journal of China University of Geosciences, vol. 44, no. 11, pp. 36533661, 2019.

[80] H. K. Nie, D. H. Li, G. X. Liu, Z. Y. Lu, and G. G. Zhang, “An overview of the geology and production of the Fuling shale gas field, Sichuan basin, China," Energy Geoscience, vol. 1, no. 3-4, pp. 147-164, 2020. 